Published in final edited form as:

Nat Neurosci. 2018 May ; 21(5): 707-716. doi:10.1038/s41593-018-0119-z.

\title{
Circuit dissection of the role of somatostatin in itch and pain
}

\author{
Jing Huang ${ }^{1,5,7}$, Erika Polgár ${ }^{2,7}$, Hans Jürgen Solinski ${ }^{1}$, Santosh K. Mishra ${ }^{1,6}$, Pang-Yen \\ Tseng $^{1}$, Noboru Iwagaki ${ }^{2}$, Kieran A. Boyle ${ }^{2}$, Allen C. Dickie ${ }^{2}$, Mette C. Kriegbaum ${ }^{1}$, Hendrik \\ Wildner $^{3}$, Hanns Ulrich Zeilhofer ${ }^{3}$, Masahiko Watanabe ${ }^{4}$, John S. Riddell ${ }^{2}$, Andrew J. \\ Todd $^{2,8}$, and Mark A. Hoon ${ }^{1,8}$
}

${ }^{1}$ Molecular Genetics Unit, Laboratory of Sensory Biology, National Institute of Dental and Craniofacial Research/NIH, 49 Convent Drive, Bethesda, MD 20892, USA 2Institute of Neuroscience and Psychology, College of Medical, Veterinary and Life Sciences, University of Glasgow, Glasgow G12 8QQ, UK ${ }^{3}$ Institute of Pharmacology and Toxicology, University of Zurich, Winterthurerstrasse 190, 8057 Zurich, and Institute of Pharmaceutical Sciences, Swiss Federal Institute of Technology (ETH) Zürich, Vladimir Prelog Weg 4, 8093 Zürich, Switzerland ${ }^{4}$ Department of Anatomy, Hokkaido University School of Medicine, Sapporo 060-8638, Japan

\begin{abstract}
Stimuli that elicit itch are detected by sensory neurons that innervate the skin. This information is processed by the spinal cord; however, the way in which this occurs is still poorly understood. Here we investigated the neuronal pathways for itch neurotransmission, in particular the contribution of the neuropeptide somatostatin. We find that in the periphery, somatostatin is exclusively expressed in Nppb neurons, and we demonstrate that $\mathrm{Nppb} /$ somatostatin-cells function as pruriceptors. Employing chemogenetics, pharmacology and cell-specific ablation methods, we demonstrate that somatostatin potentiates itch by inhibiting inhibitory dynorphin neurons, which results in disinhibition of GRPR neurons. Furthermore, elimination of somatostatin from primary afferents and/or from spinal interneurons demonstrates differential involvement of the peptide released from these sources in itch and pain. Our results define the neural circuit underlying somatostatin-induced itch, and characterize a contrasting anti-nociceptive role for the peptide.
\end{abstract}

Users may view, print, copy, and download text and data-mine the content in such documents, for the purposes of academic research, subject always to the full Conditions of use:http://www.nature.com/authors/editorial_policies/license.html\#terms

${ }^{8}$ To whom correspondence should be addressed, mark.hoon@nih.gov, andrew.todd@glasgow.ac.uk.

${ }^{5}$ Present address: Department of Anatomy, Histology and Embryology, K.K. Leung Brain Research Centre, The Fourth Military Medical University, Xi' an 710032, PR China

6resent address: Department of Molecular Biomedical Sciences, College of Veterinary Medicine, North Carolina State University, Raleigh, NC; Comparative Medicine Institute, North Carolina State University, Raleigh, NC, USA.

${ }^{7}$ Co-first authors

Author Contributions

J.H., E.P., J.S.R., A.J.T., and M.A.H. designed the experiments. J.H., E.P., S.K.M., H.J.S., P-Y. T., M.K, N.I., K.A.B., and A.C.D. performed experiments. H.W. and H.U.Z. provided assistance, and M.W. provided reagents. A.J.T. and M.A.H. wrote and edited the paper, with comments from all other authors.

Competing financial interests

The authors declare no competing financial interests. 


\section{Introduction}

The somatosensory system helps us evaluate our environment, for instance alerting us to harmful or potentially damaging conditions. Through this system noxious stimuli generate itch and pain percepts. The sensation of itch, which warns us to the presence of organisms or substances on or in the skin, triggers removal of these agents. In contrast, painful stimuli produce immediate escape to prevent tissue damage. The presence of painful and itchinducing stimuli is detected by sensory neurons with cell bodies in the dorsal root ganglion (DRG) or trigeminal ganglion. These nociceptive and pruriceptive neurons transmit signals to the dorsal horn of the spinal cord or spinal trigeminal nucleus.

Many different agents elicit itch and it is thought that these are detected by specific populations of pruriceptive primary afferent neurons1. One class, those that express the MrgA3 receptor, are likely dedicated for the detection of pruritogens2. Another population expresses the neuropeptide Nppb, and since Nppb is necessary for itch behavior, it has been suggested that these neurons also function as pruriceptors3. Nppb is thought to transmit signals from peripheral afferents to cells in the dorsal horn that express Npr1 (the receptor for Nppb)3. Upon activation, these neurons are believed to release GRP, which in turn activates interneurons that express GRPR4. Npr1- and GRPR-expressing interneurons are both selectively required for itch sensation, suggesting a specific neuronal circuit for itch3,5.

Recently, molecular approaches have started to uncover mechanisms for somatosensory information processing in the spinal cord6, and these reveal that the dorsal horn is a site of considerable integration of sensory signals $7-11$. Itch can be suppressed by other sensory inputs (counter-stimuli), e.g. biting or scratching, and this seems to involve modulation within the dorsal horn. The neurons that mediate the suppression of itch by counterstimulation are thought to include a group of inhibitory cells known as B5-I neurons, because they depend on expression of the transcription factor Bhlhb5. Mice lacking B5-I neurons show exaggerated itch responses, suggesting that itch is inhibited by tonic or feedforward input from these cells12. The B5-I neurons, which account for around one third of inhibitory interneurons in the superficial dorsal horn, can be subdivided into two populations: those that express the neuropeptides dynorphin and galanin, and those that contain neuronal nitric oxide synthase (nNOS)13-15. Dynorphin inhibits itch, suggesting that B5-I neurons may suppress itch at least partly through dynorphin/kappa opioid receptor (KOR) signaling. However, Duan et al recently concluded that dynorphin-expressing spinal cord neurons were not involved in suppressing itch9. There is therefore doubt about which cells are responsible for B5-I-mediated itch suppression.

The inhibitory neuropeptide somatostatin is expressed in a small population of DRG neurons 16. Transcriptomic studies indicate that these correspond to cells that express Nppb, together with several itch-related genes17,18 and it has recently been reported that ablation of somatostatin-expressing primary afferents caused itch deficits19. Intriguingly, intrathecal administration of somatostatin elicits scratching behavior 15 hinting that it may be involved in enhancing itch. There are conflicting reports suggesting that somatostatin can either promote or attenuate pain20-24. As well as being present in primary afferents, somatostatin is expressed by many dorsal horn excitatory interneurons 25 and these are important 
elements for transmission of mechanical pain9,26. Therefore, there is considerable uncertainty about the roles of somatostatin in itch and pain.

Here we have used multiple approaches to examine how itch sensation can be modulated by somatostatin. Using optogenetics we demonstrate that sensory neurons expressing somatostatin and Nppb function as pruriceptors, and we show that somatostatin potentiates scratching evoked by GRP, Nppb, and histamine. By using chemogenetics to interrogate subsets of B5-I neurons, we establish that $\mathrm{Sst}_{2 \mathrm{a}}$-expressing dynorphin cells are the route through which somatostatin enhances itch. Employing specific lesioning techniques, we show that the disinhibition involving dynorphin cells operates at the level of the GRPR neurons, and we thus define the complete micro-circuit through which somatostatin modulates itch. Lastly, we generated and characterized cell type-specific conditional somatostatin knockout mice, and used these to reveal that somatostatin released from both primary afferents and spinal cord interneurons is required for normal itch behavior. These experiments also establish that somatostatin released from peripheral, but not spinal neurons, plays a critical role in suppressing heat pain.

\section{Results}

\section{Somatostatin and Nppb are co-expressed in a subset of DRG neurons}

Neuropeptides are known to serve various somatosensory signaling roles 27 . We recently studied the neuropeptides neuromedin B (NMB) and Nppb, and demonstrated that they are involved in pain and itch mechanisms, respectively3,28. In addition to NMB and Nppb, there are many other neuropeptides expressed in DRG. To characterize these in greater detail we compared the expression profiles of several neuropeptides (Figures 1A and S1). Notably, the expression pattern of somatostatin is very similar to that of Nppb (Figure 1A) and single cell transcriptomic analyses suggest that they are co-expressed17,18,29. To determine the extent of overlap in expression of these neuropeptides, we performed double-label in situ hybridization (ISH). Figure 1B shows that there was virtually complete co-expression (99\% overlap: 161/163 Sst/Nppb-neurons). This raised questions of how these neuropeptides are used by the same neuron, and what is the function of these neurons.

\section{Optogenetic activation of somatostatin-expressing primary afferent neurons elicits itch- behavior}

Previously, we demonstrated that Nppb is both necessary and sufficient to produce itch behavior3, suggesting that $\mathrm{Nppb} /$ somatostatin neurons function as pruriceptors. The tight correspondence in gene expression of somatostatin and Nppb allowed us to test this by genetically manipulating these neurons in mice in which Cre is knocked into the somatostatin locus ( $S_{s} t^{\mathrm{Cre}}$ ), as was performed recently 19. We first investigated whether Cre mediates appropriate reporter expression in $S_{s l}{ }^{\mathrm{Cre}}$ mice. Double-label ISH analysis of tissue from reporter-crossed mice ( Sst $^{\mathrm{Cre}}$;Ai9) demonstrates that the majority of reporter-labeled neurons co-express Nppb (Figure S2A; 107/139 tdT-labeled neurons are Nppb-positive) and fibers from these neurons innervate the skin (Figure S2B). This indicates that ${ }_{s s} C^{\mathrm{Cre}}$ marks the majority of somatostatin-expressing primary afferents. The rodent cheek itch model is widely used to distinguish itch and pain behaviors, and we adapted this by replacing 
pruritogen injection with optogenetic stimulation. We expressed channelrhodopsin (ChR2) in somatostatin neurons ( $\mathrm{Ss}_{\mathrm{t}} \mathrm{Cre}$;Ai32 mice). To ensure that $\mathrm{ChR} 2$ was not expressed in MrgA3 pruriceptors2, we analyzed co-expression of ChR2 with both Nppb and MrgA3 (Figure 2A). We found that the majority of Cre-mediated expression (of ChR2) was restricted to Nppb-positive neurons (130 of 176). In addition, almost no MrgA3-expressing neurons co-expressed ChR2 (1 of 176). This confirms that the Nppb- and MrgA3-expressing neurons are separate populations 17,18,29. To establish that somatostatin neurons can be optogenetically activated and determine the frequency they can follow, we initially measured responses to light in isolated sensory neurons (Figure S2C). Somatostatin neurons could follow optogenetic activation up to $20 \mathrm{~Hz}$, and we used this frequency for behavioral assays. We activated the ChR2-expressing somatostatin neurons through a light cannula surgically implanted within $1 \mathrm{~mm}$ of the dorsal surface of the trigeminal ganglion (Figure 2B). Remarkably, optogenetic activation produced robust scratching responses localized to the ipsilateral cheek (Figure 2C). Responses to optogenetic stimulation were similar to those induced by injection of histamine into the cheek, except that optogenetic stimulation only elicited scratching, while histamine also evoked cheek wipes. We observed almost no scratching of the contralateral cheek, and no behavioral responses to illumination with a non-activating wavelength of light. These results demonstrate that activating somatostatin afferents is sufficient to generate selective itch behavior.

\section{Somatostatin interacts with both Nppb and GRP in itch signaling}

Our optogenetic experiments showed that itch can be induced by activation of somatostatinexpressing primary afferents, suggesting that somatostatin released from these cells acts as an itch transmitter. However it is unclear how somatostatin interacts with the itch transmitters Nppb and GRP3,4. A simple model would posit that the three neuropeptides interact in such a way as to have additive effects on itch. To investigate this we measured scratching elicited by Nppb and GRP alone, and compared the responses with those elicited by Nppb and GRP co-administered with the somatostatin receptor agonist octreotide. Furthermore, we compared Nppb- and GRP-induced scratching with that evoked by coadministration of Nppb or GRP together with the specific somatostatin Sst2 receptor antagonist CYN 154806. We predicted that if somatostatin is a transmitter involved in GRPand Nppb-induced itch, then octreotide would increase scratching induced by these neuropeptides, while CYN 154806 would have the opposite effect. Indeed, we found that octreotide potentiated Nppb- and GRP-induced itch behavior, whereas CYN 154806 attenuated these responses (Figure 3A, B). CYN 154806 also attenuated histamine-induced itch behavior, as would be expected if somatostatin has a physiological role in itch (Figure 3C). This indicates that somatostatin, GRP and Nppb are transmitters in a connected itch circuit.

\section{Spinal inhibition of itch involves the dynorphin subset of B5-I neurons}

Previously, somatostatin was shown to hyperpolarize B5-I interneurons, and the itching caused by intrathecal octreotide was absent in mice lacking these neurons 15 . This led to the suggestion that somatostatin-induced itch was mediated by disinhibition involving these cells. However, it was subsequently reported that B5-I neurons are not involved in itch behavior9. Furthermore, B5-I neurons can be subdivided into two populations, which show 
only limited ( 20\%) overlap, based on expression of dynorphin and nNOS13,15, and it was not clear which of these was involved in modulating itch. We therefore investigated which type of B5-I neurons is required for pruritogen- and somatostatin-induced itch by manipulating the activity of either dynorphin- or nNOS-neurons. We engineered mice in which we could individually interrogate these populations, based on expression of designer receptors exclusively activated by designer drugs (DREADDs)30 (Figure 4A). Specifically, we injected AAV coding for Cre-dependent Gq-coupled DREADD hM3Dq (DREADDq) fused to mCherry into one side of the lumbar dorsal horn31 of Pdyn ${ }^{\mathrm{Cre}}$ and $n N O S^{\mathrm{CreERT} 2}$ mice (Figure 4B). Importantly, we found that AAV-infection resulted in expression of mCherry in the appropriately targeted populations, and that chemogenetic activation of neurons with clozapine-N-oxide (CNO) caused Fos expression in the majority (92-95\%) of mCherry-positive cells, confirming that both populations were activated (Figure 4B-D, Figure S3). In both genotypes mCherry-positive cells were most numerous in laminae I-II and scattered through deeper laminae, consistent with the distribution of cells that express nNOS and preprodynorphin (PPD). nNOS-cells can be readily detected with immunocytochemistry and we confirmed that in $n N O S^{\text {CreERT2 }}$ mice, 429/431 (99.5\%) of the mCherry-expressing cells in laminae I-II were nNOS-immunoreactive. Since both nNOS and dynorphin are also expressed in some excitatory interneurons, we confirmed expression of mCherry and Fos in inhibitory interneurons by immunostaining for the transcription factor Pax2 and/or the $\mathrm{Sst}_{2 \mathrm{a}}$ receptor, both of which are restricted to inhibitory interneurons in this region15,31,32. Close to the injection sites in the $n N O S^{\mathrm{CreERT} 2}$ mice, mCherry was present in 71.8\% (range 58.8-91.7\%) of $\mathrm{Sst}_{2 \mathrm{a}}{ }^{+}$(inhibitory) nNOS-cells. In the Pdyn ${ }^{\mathrm{Cre}}$ mice $44 \%$ (range 33.8-50.8\%) of cells that contained both Pax2 and $\mathrm{Sst}_{2 \mathrm{a}}$ were mCherry-positive, and since PPD is present in $54 \%$ of $\mathrm{Sst}_{2 \mathrm{a}}{ }^{+}$neurons in laminae I-II13, we estimate that $82 \%$ of inhibitory dynorphin cells expressed DREADDq in this region. We also confirmed that the DREADDq was not expressed in primary afferents, by examining ipsilateral L4 DRGs (4 mice of each genotype) and observing that there were no mCherry-immunoreactive neurons in any of these ganglia (Figure S4).

If somatostatin induces itch by a disinhibitory mechanism involving B5-I neurons, we would expect that chemogenetic activation of one or both of these populations would attenuate pruritogen-evoked itch behavior by increasing inhibitory tone. Consistent with this prediction, we found that activation of dynorphin-neurons with CNO markedly attenuated itch responses to the itch-inducing agent chloroquine injected intradermally into the ipsilateral calf (Figure 4E and Figure S4). In contrast, activation of nNOS-neurons had no effect on pruritogen-induced itch (Figure 4E). Furthermore, in a separate series of experiments involving $P d y n^{\mathrm{Cre}}$ mice, we tested the effect of intrathecal administration of AAV coding for DREADDq on itch behavior in response to pruritogens injected into the nape of the neck. Administration of $\mathrm{CNO}$ to activate the dynorphin neurons attenuated both histamine- and chloroquine-evoked itch. Notably scratching evoked by intrathecal administration of octreotide was also attenuated when the dynorphin neurons were activated by $\mathrm{CNO}$ (Figure 4F), consistent with the suggestion that somatostatin induces itch by a disinhibitory mechanism involving the dynorphin-neurons.

Since activation of nNOS-neurons did not alter itch behavior, we investigated their function by testing other somatosensory modalities. Additionally, we wondered whether, as well as 
their anti-pruritic role, dynorphin neurons could modulate responses to other stimuli. We therefore examined behavioral responses to noxious thermal and mechanical stimulation following chemogenetic activation of dynorphin and nNOS-neurons in lumbar dorsal horn. Interestingly, activation of nNOS-neurons decreased sensitivity to both noxious heat and mechanical stimuli (Figure 5A, B), suggesting that they have an anti-nociceptive, but not an anti-pruritic, role. Surprisingly, we found that as well as inhibiting itch, chemogenetic activation of dynorphin neurons markedly increased sensitivity to von Frey hairs, although it had no effect on responses to heat stimulation (Figure 5A, B). This pro-nociceptive effect is likely mediated through activation of dynorphin-expressing excitatory interneurons, as these consistently showed Fos expression after treatment with $\mathrm{CNO}$, and included vertical cells (Figures S3A, S5A), which are thought to innervate nociceptive projection neurons in lamina I33. Interestingly, we noticed that mCherry-labelled excitatory cells were particularly numerous in the medial third of the dorsal horn, where they accounted for $~ 50 \%$ of the mCherry population, whereas they only constituted $12 \%$ of mCherry cells elsewhere in the superficial laminae. We recently reported that PPD-expressing excitatory neurons are concentrated in the medial part of laminae I-II in the L4 segment, suggesting an association with regions innervated by glabrous skin 13 . To confirm this, we immunostained sections through lumbar and cervical enlargements of wild-type mice and compared the distribution of inhibitory $\left(\mathrm{Pax}^{+}\right)$and excitatory (Pax2 $\left.2^{-}\right)$PPD-immunoreactive neurons. In both enlargements, the excitatory cells were largely restricted to glabrous skin territory, identified by lack of input from VGLUT3-expressing C-low threshold mechanoreceptors, which are restricted to hairy skin34 (Figure 5C-G and Figure S5B, C). It is therefore likely that excitatory dynorphin neurons are largely restricted to regions of dorsal horn innervated by glabrous skin, and that they accounted for the mechanical hyperalgesia that we observed when von Frey hairs were applied to the plantar surface of the foot. The calf itch model activates cells in the middle third of the superficial dorsal horn within the L3 segment35. Excitatory PPD cells were rarely present in this region (Fig 5C-G), and are therefore unlikely to be involved in the anti-pruritic effect seen in the CNO-treated mice. Together, these results establish that dynorphin- and nNOS-containing interneurons modulate responses to several sensory modalities and produce distinct behavioral effects.

\section{Somatostatin and dynorphin interact with Nppb signaling at the level of GRPR neurons}

Previously it was reported that dynorphin can attenuate itch through the KOR and that KOR antagonists can induce itch15. However, it is unclear how dynorphin acting on KORs modulates the itch evoked by somatostatin and Nppb. To examine this, we again took a pharmacological approach to determine the sequence in the itch pathway involving these neurotransmitters. First, our results place dynorphin downstream of somatostatin (Figure 4F), therefore we reasoned that the KOR agonist ICI199441 should block scratching responses induced by octreotide15. Second, it follows that if the somatostatin receptor is upstream of the action of KOR, we would predict that administration of somatostatin receptor antagonist would not affect itch induced by the KOR antagonist norbinaltrorphimine. Lastly, since peripherally induced itch is inhibited by KOR agonist, then scratching evoked by histamine and Nppb should also be attenuated by KOR agonist 15 . As expected, we found that KOR agonist attenuated somatostatin-induced itch, that KOR antagonist-induced itch was unaffected by somatostatin receptor antagonist, and that both 
histamine- and Nppb-induced itch were also attenuated by KOR agonist (Figure 6A, B). Together these results further substantiate the pathway for somatostatin-induced itch, through disinhibition involving the dynorphin subset of B5-I neurons, and provide additional evidence that this pathway interacts with Nppb signaling.

Our results indicate that somatostatin-induced itch is mediated through disinhibition involving dynorphin-expressing interneurons, and that somatostatin can potentiate Nppb signaling. However, the site of interaction between these pathways is unknown. This could be at the level of either Npr1-neurons, or GRPR-neurons. To investigate this, we used conjugated toxins to generate selective lesions in the Nppb and GRP pathways3,5 and we pharmacologically blocked GRPR. Specifically, we used Nppb-saporin and GRP-saporin to ablate Npr1- and GRPR-expressing dorsal horn neurons, respectively, and we inhibited GRPR with GRPR antagonists. By exploiting octreotide- and KOR antagonist-triggered itch behavior, we could then examine the requirement of Nppb and GRP neurons for these types of itch. We reasoned that a block at the site of intersection would attenuate itch-responses while a block upstream of this site would not. As expected, we found that one population of neurons was required: ablation of GRPR neurons, and treatment with GRPR antagonist, profoundly reduced the itch elicited by both octreotide and KOR antagonist, as well as that evoked by histamine (Figure 6C-E). In contrast, elimination of Npr1 neurons attenuated histamine-induced itch, but had no effect on octreotide- and KOR antagonist-evoked itch, suggesting that somatostatin and dynorphin act downstream of Npr1-cells (Figure 6F-H). Together these data suggest a model for somatostatin-mediated itch that involves the dynorphin subset of B5-I neurons, which suppress transmission at the level of the GRPR cells (Figure 6I).

\section{Somatostatin is required for normal itch and pain responses}

Our findings suggest that the itch-inducing effect of somatostatin is mediated at least in part by dynorphin neurons. However, the origin of the somatostatin that acts on these neurons to cause itch is unknown. Somatostatin is expressed by both primary afferents and excitatory spinal cord interneurons25,36. Either or both of these populations might be the source of the somatostatin that is involved in regulating itch. To address this issue, and provide further evidence that somatostatin acts as a mediator of itch in vivo, we generated mice in which somatostatin could be eliminated in specific cell-types (Figure 7A). The resulting $S s t^{\mathrm{f} / \mathrm{f}}$ mice were crossed with $\operatorname{Trp}_{V} I^{\mathrm{Cre}}, \mathrm{Lb}_{x} I^{\mathrm{Cre}}$, and $\mathrm{Wnt}_{1} I^{\mathrm{Cre}}$ lines to eliminate somatostatin from DRG neurons, dorsal horn neurons, and both classes of neurons, respectively. The resulting mice were born at expected Mendelian ratios, appeared healthy, and showed none of the phenotypic abnormalities present in global somatostatin knockout mice37. ISH confirmed selective loss of somatostatin mRNA in the expected tissues (Figure 7B). Our results from blocking the somatostatin receptor (Figure 3 ) led to the prediction that mice lacking somatostatin in the dorsal horn should display reduced responses to itch-inducing agents. To test this, we assessed behavioral responses of the mutant mice to several pruritogens. As anticipated, we found that mice lacking somatostatin in both peripheral and spinal cord neurons $\left(S s t^{\mathrm{f} / \mathrm{f}} ; \mathrm{Wnt} \mathrm{I}^{\mathrm{Cre}}\right.$ ), exhibited significant itch deficits to all pruritogens tested (Figure 7C). In contrast, mice lacking somatostatin in either primary afferents $\left(S s t^{\mathrm{f} / \mathrm{f}} ; \operatorname{Tr} p v I^{\mathrm{Cre}}\right)$, or dorsal horn interneurons $\left(S s t^{\mathrm{f} / \mathrm{f}} ; \mathrm{Lbx} I^{\mathrm{Cre}}\right)$, displayed itch behavior similar to that of control 
littermates (Figure $\mathrm{S} 6 \mathrm{AB}$ ). These results provide further evidence that somatostatin is required for itch transmission in vivo and show that somatostatin from both primary afferents and spinal cord interneurons contributes to normal itch behavior.

The finding that somatostatin released from interneurons is required for normal itch transmission led us to search for further evidence supporting such a role. We investigated $P d y n{ }^{\mathrm{Cre}}$ mice that had received spinal injections of AAV coding for Cre-dependent enhanced green fluorescent protein (eGFP), to allow visualization of dynorphin neurons. We identified $\mathrm{eGFP}^{+}$cells with tonic or transient firing patterns (characteristic of inhibitory neurons38) and found that all of these cells (8/8) were hyperpolarised by bath-applied somatostatin (Figure $\mathrm{S} 7$ ), consistent with expression of $\mathrm{Sst}_{2 \mathrm{a}}$ receptor by $91 \%$ of inhibitory dynorphin cells13. In anatomical studies, axonal boutons belonging to somatostatin-expressing interneurons can be recognized by their co-expression of somatostatin and VGLUT2, whereas somatostatin primary afferent terminals have very low or undetectable levels of VGLUT2-immunoreactivity36. We found, as expected, that most $\mathrm{eGFP}^{+}$cell bodies in superficial dorsal horn (78\%) were $\mathrm{Sst}_{2 \mathrm{a}}$-immunoreactive, and that these lay within a dense plexus of boutons that contained both somatostatin and VGLUT2, and therefore presumably originated from local somatostatin interneurons. In addition, all of the cells examined had numerous contacts from somatostatin ${ }^{+} /$VGLUT $^{+}$boutons on their cell bodies and dendrites (Figure S8). These findings suggest that somatostatin released from axons of local interneurons acts on dynorphin-expressing inhibitory interneurons to cause disinhibition.

In addition to a role in itch, somatostatin has been proposed to be either pronociceptive2224 or analgesic39,40. To investigate this, we tested the nociceptive behavior of conditional $S s t^{\mathrm{f} / \mathrm{f}}$ mice. Intriguingly, we found that mice lacking somatostatin in DRG-neurons $\left(S s t^{\mathrm{f} / \mathrm{f}} ; \operatorname{Tr} p v{ }^{\mathrm{Cre}}\right)$, displayed dramatically increased sensitivity to noxious heat (Figure 8). In contrast, $S s t^{\mathrm{f} / \mathrm{f}} ; \mathrm{Lbx}_{\mathrm{X}} \mathrm{I}^{\mathrm{Cre}}$ animals exhibited normal responses to noxious heat, while $S s t^{\mathrm{f} / \mathrm{f}} ; W n t 1^{\mathrm{Cre}}$ mice displayed responses similar to those of $S s t^{\mathrm{f} / \mathrm{f}} ; \operatorname{Trp}_{V} I^{\mathrm{Cre}}$ mice. These results indicate that somatostatin released from primary sensory neurons normally suppresses nociceptive responses. This might result from effects in the spinal cord, or be due to tonic release of somatostatin from Nppb-afferents acting on peripheral endings of nociceptive afferents, as reported previously20,21,41. Conditional $S s t^{\mathrm{f} / \mathrm{f}}$ mice also exhibit phenotypic differences in withdrawal thresholds to von Frey hairs (Figure S6C) suggesting a contribution of somatostatin to this behavior. Notwithstanding the mechanism involved, the phenotype of somatostatin-deficient mice demonstrates that somatostatin released from primary afferents contributes to the inhibition of pain.

\section{Discussion}

Here, using optogenetics, chemogenetics, pharmacology, and conditional genetic knockouts, we delineate roles for somatostatin in itch and pain sensation. First, using optogenetic activation, we show that sensory neurons that express somatostatin are sufficient to evoke itch behavior (Figure 2). Second, we demonstrate that somatostatin directly potentiates itch elicited by Nppb and GRP, and that a somatostatin receptor antagonist attenuates histaminergic itch (Figure 3). Third, genetic knockout of somatostatin establishes that it is required for normal itch behavior (Figure 7), and our studies define a disinhibitory spinal 
cord microcircuit through which somatostatin modulates itch (Figure 3, 4, and 6). Lastly, we show that somatostatin released from primary afferents is involved in inhibiting pain behavior (Figure 8). Therefore, our studies reveal, at both molecular and cellular levels, the mechanisms by which somatostatin modulates itch, and we show that somatostatin also plays an important role in heat nociception.

The co-localization of somatostatin and Nppb in a subclass of sensory neurons raised the question of how these neuropeptides interact in itch processing. Our results reveal that they act on distinct neural substrates and that the pathways engaged by these transmitters, although initially separate, converge and interact (Figure 3, 4, and 6). Although somatostatin presumably acts at least partly through dynorphin/KOR signaling to regulate itch, inhibition involving GABA and glycine has also been shown to play a critical role in suppressing pruritogen-evoked activity31,42,43. GABA, the principal fast transmitter used by the dynorphin/galanin interneurons 44 , is therefore also likely to have contributed to the antipruritic effect of stimulating the dynorphin neurons, and to be involved in somatostatinevoked itch. Since neuropeptides have a longer-lasting action than amino-acid transmitters, we suggest that peptidergic mechanisms involving somatostatin and dynorphin probably modify the excitability of neurons in the spinal cord to control longer-term behavioral responses, whereas fast transmitters underlie the rapid suppression of itch by counterstimuli. Recently another study examined the effects of chemogenetic and optogenetic activation of spinal cord somatostatin neurons, and found that this potentiated mechanical sensitivity 26 in line with the proposed role of these neurons in gating mechanical pain9. In addition, the authors reported that low-frequency optogenetic stimulation of these neurons increased histamine-evoked scratching behavior, and this effect was reduced by intrathecal administration of the somatostatin receptor antagonist CYN-154806 (250 ng)26, suggesting that it was mediated at least in part by somatostatin released from these cells. However, this finding is difficult to interpret, because we show here that intrathecal treatment with a somewhat higher dose $(1 \mu \mathrm{g})$ of CYN-154806 strongly suppresses histamine-evoked itch (Figure 3C). Nonetheless, these findings are consistent with our conclusion that somatostatin release from the spinal cord contributes to itch neurotransmission. Previously we showed that somatostatin is expressed in the majority of GRP neurons 45 , and so co-release of GRP and somatostatin from these cells could independently contribute to itch.

Molecularly defined classes of primary afferent neurons that detect and transmit signals for thermal, tactile and itch stimuli have been identified, and it has been suggested that sensation is primarily encoded by these specifically tuned receptor cells1. However, since somatostatin afferents express TRPV1, they could be activated by noxious stimuli. Nonetheless, our optogenetic findings show that selective stimulation of these cells results in itch, but not pain behaviors. This suggests that a coding mechanism allows these two types of stimulus to be distinguished. One potential mechanism would be the "leaky gate" model46. This proposes that although pruritic and nociceptive inputs converge on GRP neurons, frequency coding by these cells determines whether pain or itch behavior is evoked, through a feed-forward inhibition involving enkephalinergic neurons. As predicted by this model, Sun et al46 found that ablation of GRP cells resulted in a dramatic reduction of itch and an increase in certain types of pain. However, their ablation appears to have extended beyond the GRP neurons, since they reported a marked loss of cells that express PKC $\gamma$, which shows minimal overlap 
with GRP45,47. Loss of additional populations of excitatory interneurons therefore complicates interpretation of their behavioral findings. Consistent with the idea that somatostatin/Nppb neurons are dedicated itch chemoreceptors, the IL31Ra itch receptor is exclusively expressed by these cells $17,18,29,48$. The somatostatin primary sensory neurons are molecularly distinct from MrgA3-neurons17,18 (Figure 2) and therefore represent an additional population of pruriceptive afferents.

There has been great interest in determining the mechanisms by which circuits in the spinal cord integrate and modify incoming sensory signals. We studied the effects of activating dynorphin neurons, most of which represent a subset of B5-I cells. Consistent with the suggestion that B5-I cells include neurons responsible for suppressing itch15, and that KOR agonists act locally within the spinal cord to reduce itch (Figure 6 and reference 15), we found that chemogenetic activation of these neurons suppressed pruritogen-evoked itch behavior (Figure 4). Furthermore, in line with the view that somatostatin-induced itch is mediated through a disinhibitory mechanism, activating the dynorphin neurons also attenuated scratching evoked by intrathecally administered octreotide (Figure 4F). This antipruritic role was specific for the dynorphin neurons, since activating the other main class of B5-I cells, those that express nNOS, reduced responses to noxious stimuli but had no effect on itch behavior.

Previously, Duan et al reported that dynorphin-expressing spinal cord neurons have a role in gating mechanical pain, since mice lacking dynorphin-lineage neurons were hypersensitive to mechanical stimulation, but showed normal itch behavior9. These studies used the same $P d y n^{\text {Cre }}$ line, however, our experimental approach differed significantly from that of Duan et al. We engineered mice in which mature dynorphin neurons express DREADDq, whereas Duan et al used an intersectional ablation strategy. This would have captured inhibitory interneurons that transiently express dynorphin13, but apparently excluded excitatory dynorphin cells, as well as $\sim 40 \%$ of the galanin-expressing inhibitory neurons (see Figures 5 and S7 of Duan et al). Because of these differences, the neurons we activated only partially overlap with those that they ablated. This presumably accounts for the difference in our findings with mechanical pain tests, and also for the discrepancy between the anti-pruritic effect that we observed and the lack of a significant effect on itch reported in their study.

Our findings reveal that somatostatin is also important in controlling pain (Figure 8). In particular, they suggest that somatostatin released from primary afferents tonically suppresses responses to noxious heat. This resolves previous conflicting reports, which suggested that somatostatin could either promote or attenuate pain20-24. It has long been known that activity in pain pathways can suppress itch49. Intriguingly, our findings suggest that somatostatin released by pruriceptive primary afferents suppresses pain, meaning that itch may also inhibit pain.

The activity in pruriceptors in the skin is conveyed via the spinal cord to the brain, where the perceptual quality of itch is produced. By investigating the function of somatostatin in spinal processing, we show that it plays important roles in transmitting and integrating sensory information. In particular, we demonstrate a mechanism whereby two neuropeptides, somatostatin and $\mathrm{Nppb}$, that are released from the same primary afferent co-operate in a 
modality-specific dorsal horn circuit that underpins the evolutionarily important sensation of itch.

\section{Online Methods}

\section{Animals}

Mice were 20-30g (2-4 months old) unless otherwise stated. The following lines:

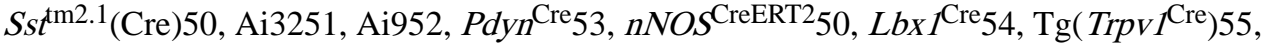
$W n t t^{\mathrm{Cre}} 56$, and $S s t^{\mathrm{f} / \mathrm{f}}\left(S s t^{\mathrm{tmla}(\mathrm{KOMP})}\right)$ were bred and inter-crossed to generate experimental animals as described in the text. All experiments using mice followed NIH guidelines and were either approved by the National Institute of Dental and Craniofacial ACUC, or were approved by the Ethical Review Process Applications Panel of the University of Glasgow and performed in accordance with the UK Animals (Scientific Procedures) Act 1986.

The targeted JM8A3 ES-cell clone F04 with knock-in insertion into the Sst gene was obtained from MBP UC Davis and was used to generate chimeric mice. Chimeras were

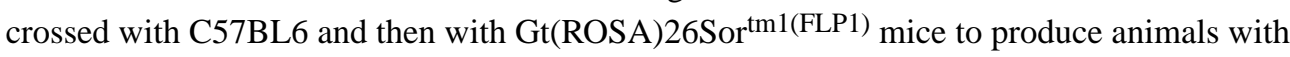
a Cre-dependent conditional Sst allele consisting of loxP sites surrounding exon 2. These mice were next crossed with $\operatorname{Tr} p v I^{\mathrm{Cre}}, W_{n t} I^{\mathrm{Cre}}$, and $\mathrm{Lbx}_{x} I^{\mathrm{Cre}}$ mice, to produce conditional knockout mice; controls were homozygous $S s t^{\mathrm{f} / \mathrm{f}}$ littermates without Cre. Age and sex matched $S s t / f$ cKO mice and littermates were used, and there were no significant phenotypic differences between sexes. Genotyping was performed with

TGGTGAGATTATGAAGAGCAAGCG, GGCAGCTGTTCCCAATAGCCATC wild-type, and TGGTGAGATTATGAAGAGCAAGCG, ATCATTAATTGCGTTGCGCCATCTC, mutant alleles.

Animals were maintained in a temperature-controlled environment with a 12-hour light/dark cycle and free access to food and water. Mice were group housed 4-5 animal per cage, except following surgical procedures when they were single housed. Unless otherwise noted, male C57BL/6N mice (Charles River) at least 6 weeks old were used for pharmacological and conjugated-peptide ablation studies.

\section{Optogenetic stimulation}

For light-mediated activation of trigeminal somatostatin neurons, $S_{s} t^{\mathrm{Cre}}$;Ai32 mice were implanted with a $200 \mu \mathrm{m}$ diameter optical fiber (Thor labs) positioned within $1 \mathrm{~mm}$ of the ganglion. Briefly, mice were anesthetized and mounted in a stereotaxic frame (Stoelting, USA). The skull was exposed and a hole drilled and fiber implanted with the following coordinates Z $6.1 \mathrm{~mm}, \mathrm{X} 1.2 \mathrm{~mm}$, and Y $2.0 \mathrm{~mm}$ to Bregma. The cannula was secured using acrylic dental cement and after the cement dried, the skin was trimmed and glued. Mice were allowed to recover and experiments were initiated approximately three weeks after surgery.

To measure optogenetic-elicited behavior mice were placed in clear plastic enclosures with an optical cannula which could rotate to allow free movement of the mouse. Behavioral responses were recorded during the experiment. Mice were habituated for $30 \mathrm{~min}$ with the tethered optical cannula. Light was delivered from a Thorlabs LED driver (1000 mA, 20 
$\mathrm{Hz}$ ). For all animals, scratching bouts were counted for 30 minutes without illumination, followed by 30 minutes with continuous $20 \mathrm{~Hz} 590 \mathrm{~nm}$ light, and finally, bouts were counted over 30 minutes with continuous $20 \mathrm{~Hz} 470 \mathrm{~nm}$ illumination. Counts of scratching bouts for individual animals were averaged over two sessions performed on consecutive days. Separate C57BL/6N mice were assessed for histamine-evoked scratching (10 $\mu$ l injected into the cheek).

For in vitro testing of the optogenetic excitation of somatostatin primary afferent neurons, DRGs from $\mathrm{Ss}_{\mathrm{C}}{ }_{\mathrm{Cre}}$;Ai32 mice were incubated with $5 \mathrm{mg} / \mathrm{mL}$ collagenase/Dispase for 30 minutes and were mechanically dissociated. Dissociated primary cultures were seeded onto poly-D-Lysine treated cover slips. DRG neurons were cultured with Dulbecco's Modified Eagle Medium/F-12 supplemented with $10 \%$ fetal bovine serum, $100 \mathrm{U} / \mathrm{mL}$ penicillin, and $100 \mu \mathrm{g} / \mathrm{mL}$ streptomycin, nerve growth factor $(100 \mathrm{ng} / \mathrm{mL})$ and glial cell-derived neurotrophic factor $(50 \mathrm{ng} / \mathrm{mL})$ for 2-4 days. Whole-cell recordings were performed on DRG neurons expressing channelrhodopsin-YFP with Axon 700B amplifier, 1440 Digitizer and pCLAMP 10 software (Molecular Devices). Bath solution contained 140mM NaCl, 4 $\mathrm{mM} \mathrm{KCl}, 2 \mathrm{mM} \mathrm{CaCl} 2,1 \mathrm{mM} \mathrm{MgCl} 2,10 \mathrm{mM}$ HEPES. Pipette solution contained $140 \mathrm{mM}$ KCl, 10mM EGTA, 10mM HEPES, 3mM Mg-ATP, 0.5mM Na-GTP. Light pulses were generated by Prizmatix blue LED fiber-coupled LED light source and Prizmatix pulser in the following setting: $1 \mathrm{~Hz}: 25 \mathrm{~ms} / 975 \mathrm{~ms}$ (on/off), $5 \mathrm{~Hz}: 25 \mathrm{~ms} / 175 \mathrm{~ms}, 20 \mathrm{~Hz}: 25 \mathrm{~ms} / 25 \mathrm{~ms}$, 40Hz: $10 \mathrm{~ms} / 15 \mathrm{~ms}$.

\section{Chemogenetic activation}

Intraspinal injections were performed by using a modification of the method described by Foster et al31. Mice were anaesthetized with isoflurane and placed in a stereotaxic frame with 2 vertebral clamps attached to the T12 and L1 vertebrae. The spaces between the laminae of T12-T13 and T13-L1 vertebrae were exposed and a small incision was made in the dura on the right side of the midline in each space. A hole was drilled through the lamina of the T13 vertebra on the right hand side and an incision was also made through the dura beneath this hole. Drilling a hole through the lamina of T13, rather than removing the lamina, was used to minimize swelling and distortion of the underlying spinal cord. Injections of $300 \mathrm{nl}$ of the virus (AAV2.flex.hM3Dq-mCherry; University of North Carolina Vector Core; $7.7 \times 10^{8} \mathrm{GC}$ in $300 \mathrm{nl}$ of diluent) were made on the right hand side through each of these three incisions in the dura at a depth of $300 \mu \mathrm{m}$ below the spinal cord surface and $400 \mu \mathrm{m}$ lateral to the midline. To minimize leakage, the pipette was removed 5 minutes after the completion of each injection. Injections were made at a rate of $30 \mathrm{nl}$ per minute with a $10 \mu \mathrm{l}$ Hamilton syringe attached to a glass micropipette (inner tip diameter $40 \mu \mathrm{m}$ ) by using a syringe pump (Pump 11 Elite; Harvard Apparatus, Holliston, MA). The locations of the 3 injection sites described above were chosen to correspond to spinal segments L3, L4 and L5. Baseline behavioral tests (von Frey, Hargreaves, and Rotarod, see below) were performed 2 days before the operation, and further behavioral tests were carried out on two separate occasions ( 2 days apart) approximately 2 weeks after surgery. Mice were at least 6 weeks old when the post-operative behavioral tests were carried out. The first of these sessions involved intradermal injection of CQ into the calf and the Rotarod test, and the second session consisted of von Frey and Hargreaves tests. For the experiments involving 
$n N O S^{\text {CreERT2 }}$ mice, the animals received two IP injections of tamoxifen ( $3 \mathrm{mg}$ tamoxifen in $0.15 \mathrm{ml}$ corn oil) on two consecutive days starting on the $3^{\text {rd }}$ or $4^{\text {th }}$ day after surgery. For each of the two post-operative behavioral testing sessions, mice were randomly assigned to $\mathrm{CNO}(\mathrm{CNO} 5 \mathrm{mg} / \mathrm{kg}$ ) or vehicle IP injection groups (random.org) and the experimenter was blind to treatment type. The assignment of mice to the treatment groups was independent for each behavioral session, so that an individual animal could receive either the same treatment (CNO or vehicle) or different treatments for the two sessions. Tests were performed between 1-5 hours after $\mathrm{CNO}$ or vehicle injections31. Thermal sensitivity was tested with a Hargreaves apparatus (IITC, Woodland Hills, CA, USA). Animals were acclimatized for 1 hour in a plastic cage on a glass plate warmed to $25^{\circ} \mathrm{C}$ and then a radiant heat source was targeted to the ipsilateral (right) hind-paw 5 times with a 10 minute interval between each test. The time taken to lift the stimulated paw was measured. A cut-off time of $25 \mathrm{~s}$ was used to prevent tissue damage. Mechanical sensitivity was tested with von Frey hairs. Animals were acclimatized in a plastic cage with a wire mesh floor for 1 hour and then tested with von Frey filaments with logarithmically incremental stiffness (starting with $0.4 \mathrm{~g}$ ). Each filament was applied for $5 \mathrm{sec}$, and the presence or absence of a withdrawal response was noted. The filament with the next incremental stiffness was then applied, depending on the response to the previous filament, and this was continued until there had been 6 positive responses. The filaments were applied to the glabrous skin on the right hind paw, and a positive response was recorded when there was lifting or flinching of the paw. The 50\% withdrawal was determined by the up-down method57. To test for itch, mice were acclimatized for 2 hours in plastic observation chambers that were surrounded by mirrors such that the experimenter had an unobstructed view of the hind-limb15. We injected $100 \mu \mathrm{g}$ chloroquine dissolved in $10 \mu \mathrm{l}$ PBS intradermally into the front of the right calf, which had been shaved at least 48 hours previously. In each case, the success of the intradermal injection was confirmed by the presence of a bleb58. Mice were videorecorded for 30 mins after the CQ injection and the amount of time spent biting and licking the injection site was scored later offline. Motor co-ordination was tested by using a Rotarod (ITC) with the rod programmed to accelerate from 4 to $40 \mathrm{rpm}$ over 5 mins. During the experimental testing session, the mice were allowed two trial runs followed by 4 test runs and the average of the maximum rpm tolerated was recorded. For each mouse, the ratio of maximum rpm during $\mathrm{CNO} /$ vehicle treatment over pre-operative maximum rpm was determined. There was no significant difference in these ratios between CNO-treated and vehicle-treated mice in either the $P d y n^{\mathrm{Cre}}$ or $n N O S^{\mathrm{CreERT} 2}$ experiments ( $\mathrm{p}=0.1$ and 0.29 , respectively; two-sided t-test). Mice of both sexes were used in this part of the study, and no significant behavioral differences were observed between sexes.

For intrathecal injections, we used the method described previously59 to administer AAV2.flex.hM3Dq-mCherry; $5.1 \times 10^{9} \mathrm{GC}$ in $10 \mu \mathrm{l}$ of saline. Mice were anesthetized with isoflurane. The caudal paralumbar region, just cranial to the iliac crests, was securely held by the thumb and middle fingers of the left hand, and the index finger was placed on the tip of sixth lumbar (L6) spinous process, the highest point of the vertebral column. All intrathecal injections were delivered in a total volume of $10 \mu$. The needle was inserted into the fifth intervertebral space (L5-L6) causing a sudden lateral movement of the tail. The needle was held in position for $10 \mathrm{~s}$ and removed slowly to avoid outflow. Behavioral assays 
began 14 days after virus injection and animals were treated with $1 \mathrm{mg} / \mathrm{kg}$ CNO60. One hour after $\mathrm{CNO}$ or vehicle injection, pruritogens were injected intradermally into the nape of the neck (histamine, or chloroquine), or delivered intrathecally (octreotide) and scratching bouts counted over 30 minutes.

\section{Conjugated peptide-mediated cell ablation}

Ablation of Npr1- and GRPR-expressing spinal cord interneurons was accomplished by intrathecal (segment L3/4) injection of Nppb-saporin (4 $\mu \mathrm{g}$ in $10 \mu \mathrm{l}$; Advanced Targeting Systems) and GRP-saporin $(2.5 \mu \mathrm{g})$ respectively. We have previously shown that these treatments are highly selective for the corresponding neuronal populations3. Behavioral assays were initiated two weeks after toxin injection.

\section{Itch Behavioral Test}

All other itch tests were performed as previously described3. Briefly, mice were habituated for 1 hour at room temperature in separate, clear, plastic containers $(10 \times 10 \times 12 \mathrm{~cm})$. The experimenter was blinded to genotype. Itch-inducing substances histamine, $100 \mu \mathrm{g}$, chloroquine, $100 \mu \mathrm{g}$, SLIGRL-NH $2,100 \mu \mathrm{g}$, 2-methyl serotonin, $30 \mu \mathrm{g}$, endothelin, $25 \mathrm{ng}$, and compound 48/80, $100 \mu \mathrm{g}$ were injected intradermally into the nape of the neck (10 $\mu \mathrm{l})$ and numbers of scratching bouts directed to the nape of the neck assessed over 30 minutes. We cannot completely eliminate the possibility that we were observing nociceptive rather than pruritic behaviors, but since we used established pruritogens in these assays we interpret the scratching responses we measured as itch-behavior. Itch behavior was also

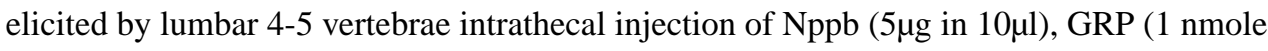
in $10 \mu \mathrm{l}$ ), and octreotide (10 $\mathrm{ng}$ and $100 \mathrm{ng}$ in $10 \mu \mathrm{l}$ as indicated in the text), all prepared in saline. Intrathecal pretreatment with GRP antagonist deamino-Phe19,D-Ala24,D-Pro26-DPhe27-GRP ( $1 \mathrm{nM}$ in $10 \mu \mathrm{l}$ ) was used to block the GRPR, Sst2-selective antagonist CYN $154806(1 \mu \mathrm{g}$ in $10 \mu \mathrm{l})$ was used to block $\mathrm{Sst}_{2 \mathrm{a}}$ receptor, the kappa-opioid receptor antagonist nor-binaltorphimine (nor-BNI, 100 ug in $10 \mu \mathrm{l}$ ) was used to block kappa-opioid receptor, and the kappa-opioid receptor agonist ICI $199441(0.1 \mu \mathrm{g}$ in $10 \mu \mathrm{l})$ was used to activate kappa-opioid receptor, all prepared in saline. We performed intrathecal injections with the same volume of dye solutions as we used in our assays, and observed staining of lumbar, thoracic, and cervical regions of the spinal cord, showing that this route of administration causes injected agents to spread along the entire spinal cord. The intrathecal administration of known pruritic agents, e.g. GRP and octreotide, predominantly resulted in scratching directed toward the nape of the neck and we observed only minor lower body evoked responses. Since the nape of the neck appears to be particularly sensitive to intrathecal administration, we recorded this behavior.

\section{In Situ Hybridization}

Single and double label ISH was performed at high stringency as described previously3. The probe used to test $S s t^{\mathrm{f} / \mathrm{f}}$ mice corresponded to the entire exon2 of $S s t$. ISH experiments quantifying overlap of somatostatin with $\mathrm{Nppb}$, and somatostatin with tdTomato were performed on 2-3 sections prepared from three wild-type and three $S_{s} t^{\mathrm{Cre}}$;Ai9 mice respectively and representative images are displayed. RNAscope, a multiplexed fluorescent 
in situ hybridization technique (Advanced Cell Diagnostics), was performed according to the manufacturer's instructions on fresh frozen tissue sections.

\section{Behavioral testing of $S s t^{f / f}$ mice}

Thermal sensitivity was tested with a Hargreaves apparatus (Ugo-Basile). Animals were acclimatized for 1 hour in a plastic cage on a glass plate. A radiant heat source was targeted to the plantar surface of the hind-paw and withdrawal latency measured. A cut-off time of 20 $\mathrm{s}$ was used to prevent tissue damage. For von Frey measurements, mice were acclimatized in a plastic cage with a wire mesh floor for 1 hour and then tested with von Frey filaments with logarithmically incremental stiffness (starting with $0.4 \mathrm{~g}$ ). Each filament was applied for 5 sec, to the hind paw and the presence or absence of a withdrawal response was noted. The filament with the next stiffness was then applied, depending on the response to the previous filament, and this was continued until 6 positive responses were recorded. The 50\% withdrawal was determined by the up-down method57.

\section{Immunocytochemistry for chemogenetic experiments}

All of the mice that had received intraspinal injections of AAV2.flex.hM3Dq-mCherry were deeply anaesthetised with pentobarbitone ( $30 \mathrm{mg}$ i.p.) and perfused with $4 \%$ freshly depolymerized formaldehyde after completion of the behavioral experiments. The lumbar enlargement (L3-5 segments) was post-fixed for 2 hours and cut into parasagittal sections with a vibrating blade microtome. These were processed for immunocytochemical staining as described previously61. The sections were incubated in anti-mCherry (rabbit antibody, Abcam, ab167453, 1:2000) for 3 days at $4^{\circ} \mathrm{C}$ and this was revealed with fluorescent-labelled species-specific secondary antibodies (Jackson Immunoresearch, West Grove, PA, USA). All antibodies were diluted in phosphate-buffered saline containing 0.3\% Triton-X100 and 5\% normal donkey serum. Sections were scanned with a Zeiss LSM 710 confocal microscope to confirm adequate expression of the hM3Dq-mCherry fusion protein in the appropriate spinal segments. In rare cases intraspinal injections were not successful, as judged by lack of mCherry staining in the appropriate spinal segments, and in these cases the corresponding behavioral data were excluded from the study.

In order to determine the neurochemical phenotype of neurons that expressed the mCherry fusion protein and to examine Fos staining following chemogenetic activation, a further 5 mice of each genotype received intraspinal injections of AAV2.flex.hM3Dq-mCherry into the $\mathrm{L} 3$ and $\mathrm{L} 5$ segments. These mice were injected with either $\mathrm{CNO}(\mathrm{n}=3$ mice per genotype) or vehicle ( $n=2$ mice per genotype), and two hours later they were perfused with fixative, as described above. Transverse spinal cord sections were cut from the L3 and L5 spinal segments. Sections from $n N O S^{\text {CreERT2 }}$ mice were immunostained for mCherry (chicken antibody Abcam, ab205402, 1:10,000), nNOS (rabbit antibody, Millipore, 07-571, 1:2000), Sst 2 a (guinea pig antibody, Gramsch Laboratories, SS-870, 1:2000) and Fos (goat antibody, Santa Cruz biotech, sc52-G, 1:2000). Sections from $P d y n{ }^{\text {Cre }}$ mice were reacted for mCherry (chicken antibody), Sst $2 \mathrm{a}$, Pax2 (rabbit antibody, Life Technologies, 716000, 1:1000) and Fos. Two sections from each mouse were analysed with Neurolucida software (MBF, Bioscience, Williston, VT, USA). All cells in the superficial dorsal horn (laminae III) that were mCherry-immunoreactive were identified. The stained neurons were then 
examined for the presence of the other markers. In addition, to determine the proportion of Fos cells that were mCherry-immunoreactive, we counted neurons that were Fos-positive but lacked mCherry. Note that for technical reasons we did not use antibodies against preprodynorphin (PPD) as our PPD antibody is raised in guinea pig, the same species as the $\mathrm{Sst}_{2 \mathrm{a}}$ antibody, and in addition PPD may be below the detection threshold to allow unambiguous identification of all dynorphin-expressing neurons.

Both mCherry antibodies were raised against recombinant full-length protein corresponding to mCherry. Specificity is demonstrated by the finding of an identical distribution of staining to that seen with native fluoresence of mCherry protein, and by the lack of staining in regions of tissue that do not contain mCherry. The Fos antibody was raised against a peptide corresponding to the N-terminus of human Fos, and its specificity has been shown in previous studies by the restriction of staining to neurons in somatotopically appropriate areas after noxious or pruritic stimulation61. The nNOS antibody was directed against a synthetic peptide corresponding to $\mathrm{N}$ terminus of rat $\mathrm{nNOS}$ and labels a single band of $155 \mathrm{kDa}$ in rat brain extracts. The antibody against Pax 2 was raised against amino acids 188 to 385 of the mouse protein and recognizes bands of the appropriate size on Western blots of mouse embryonic kidney62. The $\mathrm{Sst}_{2 \mathrm{a}}$ antibody was generated against the $\mathrm{C}$ terminal 15 amino acids of the mouse receptor, and staining is abolished by incubation with the immunizing peptide (manufacturer's specification).

\section{Distribution of excitatory and inhibitory dynorphin cells}

Three wild-type C57BL/6 mice (either sex, 19-20 g) were perfused with fixative as described above. Spinal cord segments L3, L4 and L5 were removed from all 3 mice and C6, C7 and C8 from 2 mice. In each case, the segments were cut into 4 sets of transverse sections, one of which was immunoreacted to reveal Pax2, PPD and NeuN, and one to reveal VGLUT3. The tyramide signal amplification method (TSA kit tetramethylrhodamine NEL702001, PerkinElmer Life Sciences, Boston, MA, USA) was used to reveal PPD and VGLUT3. Two or 3 sections that had been reacted with the first antibody combination were analysed by using a modification of the disector method13. All PPD-immunoreactive neurons with the bottom surface between reference and look-up sections were initially plotted onto an outline of the dorsal horn, and then the presence or absence of Pax2 staining was recorded for each selected cell. The sections that had been reacted with VGLUT3 antibody were then examined, and those that were closest in appearance to the sections analysed for PPD were scanned. The medial edge of the band of VGLUT3 staining, which represents hairy skin territory, was located and added to the outline drawing. The PPD antibody63 was raised against a peptide corresponding to amino acids 229-248 at the C terminus of rat PPD, and has been shown to label PPD, but not dynorphin or enkephalin. The $\mathrm{NeuN}$ antibody was raised against cell nuclei extracted from mouse brain and found to react with a protein specific for neurons64, which has subsequently been identified as the splicing factor Fox-3. The antibody against VGLUT3 was raised against amino acids 522-588 of the mouse protein and detects a single protein band at 60-62 kDa. 


\section{Somatostatin action on dynorphin cells}

Eight $P d y n^{\mathrm{Cre}}$ mice of either sex (18-23 g, aged 5-9 weeks) received intraspinal injections of AAV.flex.eGFP $\left(4.3 \times 10^{8}-1.7 \times 10^{9} \mathrm{GC}\right.$ in $300 \mathrm{nl}$ diluent). These were performed as described above, except that injections were made through incisions on either side of the T13 vertebra into the L3 or L5 segments, and the mice survived between 7 and 11 days after surgery.

Five of these animals were used for electrophysiological experiments. The animals were decapitated under general anaesthesia with isoflurane (1-3\%). Spinal cords were isolated in ice-cold dissecting solution that contained the following (in $\mathrm{mM}$ ): $3.0 \mathrm{KCl}, 1.2 \mathrm{NaH}_{2} \mathrm{PO}_{4}$, $0.5 \mathrm{CaCl}_{2}, 1.3 \mathrm{MgCl}_{2}, 8.7 \mathrm{MgSO}_{4}, 26 \mathrm{NaHCO}_{3}, 20$ HEPES, 25 glucose, 215 sucrose, oxygenated with $95 \% \mathrm{O}_{2}$ and $5 \% \mathrm{CO}_{2}$. The dura mater was removed, and ventral and dorsal roots were trimmed close to the cord. The lumbar segments containing the injection site were cut into parasagittal slices $(300 \mu \mathrm{m})$ with a vibrating blade microtome (MicromHM $650 \mathrm{~V}$, Fisher Scientific). Slices were held in the dissecting solution at room temperature for at least $30 \mathrm{~min}$, and then transferred into recording solution that contained the following (in $\mathrm{mM}$ ): $126 \mathrm{NaCl}, 3.0 \mathrm{KCl}, 1.2 \mathrm{NaH}_{2} \mathrm{PO}_{4}, 2.4 \mathrm{CaCl}_{2}, 1.3 \mathrm{MgCl}_{2}, 26.0 \mathrm{NaHCO}_{3}, 15$ glucose, oxygenated with $95 \% \mathrm{O}_{2}, 5 \% \mathrm{CO}_{2}$. GFP-positive cells found within the superficial dorsal horn (mostly lamina II) were targeted for whole-cell patch-clamp recording, under fluorescent and infrared differential interference contrast microscopy on an Olympus BX51WI microscope. Patch pipettes were pulled with a horizontal puller (P-97, Sutter Instruments) from glass capillaries (Harvard Apparatus). The pipettes typically had an electrical resistance of $4-6 \mathrm{M} \Omega$ when filled with internal solution, which contained the following (in $\mathrm{mM}$ ): 130 potassium gluconate, $10 \mathrm{KCl}, 2 \mathrm{MgCl}_{2}$, 10 HEPES, 0.5 EGTA, 2 ATP-Na $a_{2}, 0.5$ GTP-Na, pH adjusted to 7.3 with $1 \mathrm{M} \mathrm{KOH}$. Neurobiotin $(0.2 \%$, Vector Laboratories) was also included in the internal solution for subsequent identification of recorded cells. Patch-clamp signals were amplified and filtered (4 kHz low-pass Bessel filter) with a MultiClamp 700B amplifier (Molecular Devices) and acquired at $10 \mathrm{kHz}$ using a Digidata 1440 A A/D board and pClamp 10 software (Molecular Devices). When wholecell mode was established, the cell was presented with voltage and current step protocols to have its intrinsic membrane properties assessed. While holding the cell at $-60 \mathrm{mV}$, voltage steps from -90 to $-50 \mathrm{mV}$ (500 ms, $5 \mathrm{mV}$ increments) were applied in order to allow the current-voltage $(I-V)$ relationship to be obtained. In current-clamp mode, steps of square current pulse (1 s) were injected to evoke action potentials. Patterns of action potential firing were classified as described previously38. To minimize the chance of sampling excitatory interneurons we excluded cells that showed delayed or gap firing patterns, which are associated with an excitatory phenotype 38 . Somatostatin ( $2 \mu \mathrm{M}$, Tocris Bioscience) was administered via the recording solution, and any change in membrane potential was recorded in current-clamp mode. Around 5 minutes after the start of somatostatin application, the same voltage and current step protocols were repeated to assess somatostatin-mediated modulatory effects in the recorded cell $(n=8)$.

Three of the $P d y n^{\mathrm{Cre}}$ mice that had received intraspinal injection of AAV.flex.eGFP were deeply anaesthetised and perfused with fixative. Injected spinal cord segments were removed and processed for immunocytochemistry as described above. Parasagittal sections were 
immunoreacted to reveal $\mathrm{Sst}_{2 \mathrm{a}}$, somatostatin (rabbit antibody, Peninsula labs, T-4103, 1:500) and VGLUT2 (chicken antibody, Synaptic systems, 135416, 1:500). Five $\mathrm{eGFP}^{+}$cells that were $\mathrm{Sst}_{2 \mathrm{a}}$-immunoreactive were selected from each mouse before immunostaining for somatostatin was observed, and these were scanned with a confocal microscope to include as much of the dendritic tree as was visible in the section. The cell bodies and dendritic trees were reconstructed with Neurolucida software based on eGFP fluorescence. The other channels were then viewed, and contacts from somatostatin ${ }^{+} /$VGLUT2 $^{+}$boutons were marked. The VGLUT2 antibody was raised against a synthetic peptide corresponding to aminoacids 566-582 of rat VGLUT2 and detects a single band of appropriate molecular weight on Western blots (manufacturer's specification). The somatostatin antibody is reported to show $100 \%$ cross-reactivity with somatostatin- 28 and somatostatin- 25 , but none with substance $\mathrm{P}$ or neuropeptide $\mathrm{Y}$, and staining is blocked by preincubation with somatostatin65.

\section{Statistical analysis}

Data are expressed as mean \pm SEM. Statistical analysis was performed in Prism (GraphPad). Differences between 2 groups were examined using a two-sided Student's t test, with $\mathrm{p}<0.05$ considered significant and $p>0.05$ considered non-significant. When comparisons were made between different groups of mice ANOVA was used and when repeated effects were assessed in a single group of mice (Figure 2 only) repeated measure ANOVA was used. No statistical methods were used to pre-determine sample sizes but our sample sizes are similar to those reported in previous publications4,19,46. Data distribution was assumed to be normal but was not formally tested. Data collection was not randomized and data analysis and collection were not performed blind to the conditions of the experiment except where noted (chemogenetic experiments). Animals and data points were not excluded from analysis. All relevant data are available from authors.

\section{Supplementary Material}

Refer to Web version on PubMed Central for supplementary material.

\section{Acknowledgements}

This work was supported by the intramural research program of the National Institute of Dental and Craniofacial Research (NIDCR)-National Institutes of Health (MAH) and grants from the Medical Research Council (MR/ L003430/1), the Biotechnology and Biological Sciences Research Council (grant N006119), the Wellcome Trust (102645) (AJT), the Swiss National Science Foundation (156393) (HUZ), and the Natural Science Foundation of China (31671247) (JH).

The $S s t^{f / f}$ mice used in this study were generated from ES-cells obtained from the National Center for Research Resources (NCRR)-NIH-supported KOMP repository and engineered by the Welcome Trust Sanger Institute and the Mouse Biology Program. We thank the NIDCR Gene targeting facility for help generating chimeric $S s t^{\mathrm{f} / \mathrm{f}}$ mice. We also thank Carmen Birchmeier, Michael Krashes, and Qiufu Ma for generously providing mice. We are very grateful to Takahiro Furuta for the gift of PPD antibody, to Andrew Bell and David Hughes for comments on the manuscript, to Xinglong Gu for help in some of the experiments, and to Robert Kerr and Christine Watt for expert technical help. 


\section{References}

1. Le Pichon CE, Chesler AT. The functional and anatomical dissection of somatosensory subpopulations using mouse genetics. Front Neuroanat. 2014; 8:21. [PubMed: 24795573]

2. Han L, et al. A subpopulation of nociceptors specifically linked to itch. Nat Neurosci. 2013; 16:17482. [PubMed: 23263443]

3. Mishra SK, Hoon MA. The cells and circuitry for itch responses in mice. Science. 2013; 340:96871. [PubMed: 23704570]

4. Sun YG, Chen ZF. A gastrin-releasing peptide receptor mediates the itch sensation in the spinal cord. Nature. 2007; 448:700-3. [PubMed: 17653196]

5. Sun YG, et al. Cellular basis of itch sensation. Science. 2009; 325:1531-4. [PubMed: 19661382]

6. Braz J, Solorzano C, Wang X, Basbaum AI. Transmitting pain and itch messages: a contemporary view of the spinal cord circuits that generate gate control. Neuron. 2014; 82:522-36. [PubMed: 24811377]

7. Abraira VE, et al. The cellular and synaptic architecture of the mechanosensory dorsal horn. Cell. 2017; 168:295-310 e19. [PubMed: 28041852]

8. Cui L, et al. Identification of early RET+ deep dorsal spinal cord interneurons in gating pain. Neuron. 2016; 91:1413. [PubMed: 27657453]

9. Duan B, et al. Identification of spinal circuits transmitting and gating mechanical pain. Cell. 2014; 159:1417-32. [PubMed: 25467445]

10. Peirs C, et al. Dorsal Horn Circuits for Persistent Mechanical Pain. Neuron. 2015; 87:797-812. [PubMed: 26291162]

11. Petitjean H, et al. Dorsal horn parvalbumin neurons are gate-keepers of touch-evoked pain after nerve injury. Cell Rep. 2015; 13:1246-57. [PubMed: 26527000]

12. Ross SE, et al. Loss of inhibitory interneurons in the dorsal spinal cord and elevated itch in Bhlhb5 mutant mice. Neuron. 2010; 65:886-98. [PubMed: 20346763]

13. Boyle KA, et al. A quantitative study of neurochemically defined populations of inhibitory interneurons in the superficial dorsal horn of the mouse spinal cord. Neuroscience. 2017; 363:120133. [PubMed: 28860091]

14. Brohl D, et al. A transcriptional network coordinately determines transmitter and peptidergic fate in the dorsal spinal cord. Dev Biol. 2008; 322:381-93. [PubMed: 18721803]

15. Kardon AP, et al. Dynorphin acts as a neuromodulator to inhibit itch in the dorsal horn of the spinal cord. Neuron. 2014; 82:573-86. [PubMed: 24726382]

16. Hokfelt T, et al. Immunohistochemical evidence for separate populations of somatostatincontaining and substance P-containing primary afferent neurons in the rat. Neuroscience. 1976; 1:131-6. [PubMed: 1004708]

17. Li CL, et al. Somatosensory neuron types identified by high-coverage single-cell RNA-sequencing and functional heterogeneity. Cell Res. 2016; 26:83-102. [PubMed: 26691752]

18. Usoskin D, et al. Unbiased classification of sensory neuron types by large-scale single-cell RNA sequencing. Nat Neurosci. 2015; 18:145-53. [PubMed: 25420068]

19. Stantcheva KK, et al. A subpopulation of itch-sensing neurons marked by Ret and somatostatin expression. EMBO Rep. 2016; 17:585-600. [PubMed: 26929027]

20. Carlton SM, Du J, Zhou S, Coggeshall RE. Tonic control of peripheral cutaneous nociceptors by somatostatin receptors. J Neurosci. 2001; 21:4042-9. [PubMed: 11356891]

21. Carlton SM, et al. Somatostatin modulates the transient receptor potential vanilloid 1 (TRPV1) ion channel. Pain. 2004; 110:616-27. [PubMed: 15288402]

22. Seybold VS, Hylden JL, Wilcox GL. Intrathecal substance P and somatostatin in rats: behaviors indicative of sensation. Peptides. 1982; 3:49-54. [PubMed: 6176976]

23. Wiesenfeld-Hallin Z. Intrathecal somatostatin modulates spinal sensory and reflex mechanisms: behavioral and electrophysiological studies in the rat. Neurosci Lett. 1985; 62:69-74. [PubMed: 2866475] 
24. Chapman V, Dickenson AH. The effects of sandostatin and somatostatin on nociceptive transmission in the dorsal horn of the rat spinal cord. Neuropeptides. 1992; 23:147-52. [PubMed: 1361670]

25. Gutierrez-Mecinas M, Furuta T, Watanabe M, Todd AJ. A quantitative study of neurochemically defined excitatory interneuron populations in laminae I-III of the mouse spinal cord. Mol Pain. 2016; 121744806916629065.

26. Christensen AJ, et al. In Vivo Interrogation of Spinal Mechanosensory Circuits. Cell Rep. 2016; 17:1699-1710. [PubMed: 27806306]

27. Hokfelt T. Neuropeptides in perspective: the last ten years. Neuron. 1991; 7:867-79. [PubMed: 1684901]

28. Mishra SK, Holzman S, Hoon MA. A nociceptive signaling role for neuromedin B. J Neurosci. 2012; 32:8686-95. [PubMed: 22723708]

29. Nguyen MQ, Wu Y, Bonilla LS, von Buchholtz LJ, Ryba NJP. Diversity amongst trigeminal neurons revealed by high throughput single cell sequencing. PLoS One. 2017; 12:e0185543. [PubMed: 28957441]

30. Armbruster BN, Li X, Pausch MH, Herlitze S, Roth BL. Evolving the lock to fit the key to create a family of $\mathrm{G}$ protein-coupled receptors potently activated by an inert ligand. Proc Natl Acad Sci U S A. 2007; 104:5163-8. [PubMed: 17360345]

31. Foster E, et al. Targeted ablation, silencing, and activation establish glycinergic dorsal horn neurons as key components of a spinal gate for pain and itch. Neuron. 2015; 85:1289-304. [PubMed: 25789756]

32. Polgár E, Durrieux C, Hughes DI, Todd AJ. A quantitative study of inhibitory interneurons in laminae I-III of the mouse spinal dorsal horn. PLoS One. 2013; 8:e78309. [PubMed: 24205193]

33. Lu Y, et al. A feed-forward spinal cord glycinergic neural circuit gates mechanical allodynia. J Clin Invest. 2013; 123:4050-62. [PubMed: 23979158]

34. Li L, et al. The functional organization of cutaneous low-threshold mechanosensory neurons. Cell. 2011; 147:1615-27. [PubMed: 22196735]

35. Bell AM, Gutierrez-Mecinas M, Polgar E, Todd AJ. Spinal neurons that contain gastrin-releasing peptide seldom express Fos or phosphorylate extracellular signal-regulated kinases in response to intradermal chloroquine. Mol Pain. 2016; 121744806916649602.

36. Todd AJ, et al. The expression of vesicular glutamate transporters VGLUT1 and VGLUT2 in neurochemically defined axonal populations in the rat spinal cord with emphasis on the dorsal horn. Eur J Neurosci. 2003; 17:13-27. [PubMed: 12534965]

37. Zeyda T, Diehl N, Paylor R, Brennan MB, Hochgeschwender U. Impairment in motor learning of somatostatin null mutant mice. Brain Res. 2001; 906:107-14. [PubMed: 11430867]

38. Yasaka T, Tiong SY, Hughes DI, Riddell JS, Todd AJ. Populations of inhibitory and excitatory interneurons in lamina II of the adult rat spinal dorsal horn revealed by a combined electrophysiological and anatomical approach. Pain. 2010; 151:475-88. [PubMed: 20817353]

39. Chrubasik J, et al. Somatostatin, a potent analgesic. Lancet. 1984; 2:1208-9.

40. Taura $P$, et al. Epidural somatostatin as an analgesic in upper abdominal surgery: a double-blind study. Pain. 1994; 59:135-40. [PubMed: 7854794]

41. Bencivinni I, Ferrini F, Salio C, Beltramo M, Merighi A. The somatostatin analogue octreotide inhibits capsaicin-mediated activation of nociceptive primary afferent fibres in spinal cord lamina II (substantia gelatinosa). Eur J Pain. 2011; 15:591-9. [PubMed: 21109472]

42. Akiyama T, Iodi Carstens M, Carstens E. Transmitters and pathways mediating inhibition of spinal itch-signaling neurons by scratching and other counterstimuli. PLoS One. 2011; 6:e22665. [PubMed: 21818363]

43. Cevikbas F, et al. Synergistic antipruritic effects of gamma aminobutyric acid A and B agonists in a mouse model of atopic dermatitis. J Allergy Clin Immunol. 2017

44. Simmons DR, Spike RC, Todd AJ. Galanin is contained in GABAergic neurons in the rat spinal dorsal horn. Neurosci Lett. 1995; 187:119-22. [PubMed: 7540270]

45. Gutierrez-Mecinas M, Watanabe M, Todd AJ. Expression of gastrin-releasing peptide by excitatory interneurons in the mouse superficial dorsal horn. Mol Pain. 2014; 10:79. [PubMed: 25496164] 
46. Sun S, et al. Leaky Gate Model: Intensity-Dependent Coding of Pain and Itch in the Spinal Cord. Neuron. 2017; 93:840-853. [PubMed: 28231466]

47. Solorzano C, et al. Primary afferent and spinal cord expression of gastrin-releasing peptide: message, protein, and antibody concerns. J Neurosci. 2015; 35:648-57. [PubMed: 25589759]

48. Chiu IM, et al. Transcriptional profiling at whole population and single cell levels reveals somatosensory neuron molecular diversity. Elife. 2014; 3

49. Bautista DM, Wilson SR, Hoon MA. Why we scratch an itch: the molecules, cells and circuits of itch. Nat Neurosci. 2014; 17:175-82. [PubMed: 24473265]

50. Taniguchi $\mathrm{H}$, et al. A resource of Cre driver lines for genetic targeting of GABAergic neurons in cerebral cortex. Neuron. 2011; 71:995-1013. [PubMed: 21943598]

51. Madisen L, et al. A toolbox of Cre-dependent optogenetic transgenic mice for light-induced activation and silencing. Nat Neurosci. 2012; 15:793-802. [PubMed: 22446880]

52. Madisen L, et al. A robust and high-throughput Cre reporting and characterization system for the whole mouse brain. Nat Neurosci. 2010; 13:133-40. [PubMed: 20023653]

53. Krashes MJ, et al. An excitatory paraventricular nucleus to AgRP neuron circuit that drives hunger. Nature. 2014; 507:238-42. [PubMed: 24487620]

54. Vasyutina E, et al. RBP-J (Rbpsuh) is essential to maintain muscle progenitor cells and to generate satellite cells. Proc Natl Acad Sci U S A. 2007; 104:4443-8. [PubMed: 17360543]

55. Mishra SK, Tisel SM, Orestes P, Bhangoo SK, Hoon MA. TRPV1-lineage neurons are required for thermal sensation. EMBO J. 2011; 30:582-93. [PubMed: 21139565]

56. Danielian PS, Muccino D, Rowitch DH, Michael SK, McMahon AP. Modification of gene activity in mouse embryos in utero by a tamoxifen-inducible form of Cre recombinase. Curr Biol. 1998; 8:1323-6. [PubMed: 9843687]

57. Chaplan SR, Bach FW, Pogrel JW, Chung JM, Yaksh TL. Quantitative assessment of tactile allodynia in the rat paw. J Neurosci Methods. 1994; 53:55-63. [PubMed: 7990513]

58. Roberson DP, et al. Activity-dependent silencing reveals functionally distinct itch-generating sensory neurons. Nat Neurosci. 2013; 16:910-8. [PubMed: 23685721]

59. Hylden JL, Wilcox GL. Intrathecal morphine in mice: a new technique. Eur J Pharmacol. 1980; 67:313-6. [PubMed: 6893963]

60. Roth BL. DREADDs for Neuroscientists. Neuron. 2016; 89:683-94. [PubMed: 26889809]

61. Gutierrez-Mecinas M, et al. Preprotachykinin A is expressed by a distinct population of excitatory neurons in the mouse superficial spinal dorsal horn including cells that respond to noxious and pruritic stimuli. Pain. 2017; 158:440-456. [PubMed: 27902570]

62. Dressler GR, Douglass EC. Pax-2 is a DNA-binding protein expressed in embryonic kidney and Wilms tumor. Proc Natl Acad Sci U S A. 1992; 89:1179-83. [PubMed: 1311084]

63. Lee T, Kaneko T, Taki K, Mizuno N. Preprodynorphin-, preproenkephalin-, and preprotachykininexpressing neurons in the rat neostriatum: an analysis by immunocytochemistry and retrograde tracing. J Comp Neurol. 1997; 386:229-44. [PubMed: 9295149]

64. Mullen RJ, Buck CR, Smith AM. NeuN, a neuronal specific nuclear protein in vertebrates. Development. 1992; 116:201-11. [PubMed: 1483388]

65. Proudlock F, Spike RC, Todd AJ. Immunocytochemical study of somatostatin, neurotensin, GABA, and glycine in rat spinal dorsal horn. J Comp Neurol. 1993; 327:289-97. [PubMed: 7678841] 


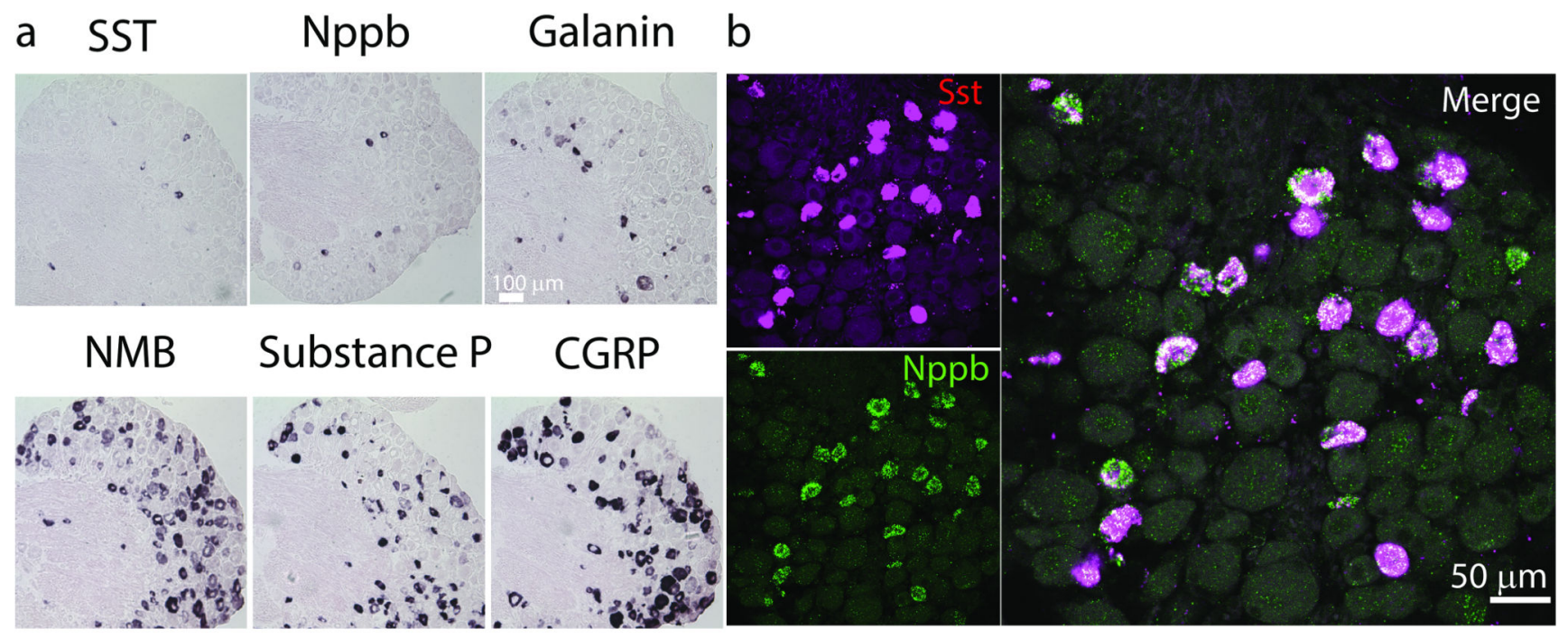

Figure 1. Somatostatin is co-expressed with Nppb in DRG neurons.

A, in situ hybridization of sections through DRG shows that different neuropeptides are expressed in subsets of sensory neurons; SST, somatostatin, Nppb, natriuretic polypeptide B, NMB, neuromedin B, CGRP, calcitonin gene related peptide. B, double label ISH reveals that somatostatin-expressing neurons (magenta) co-express the neuropeptide Nppb (green). Similar results were obtained from 3 mice. 
a

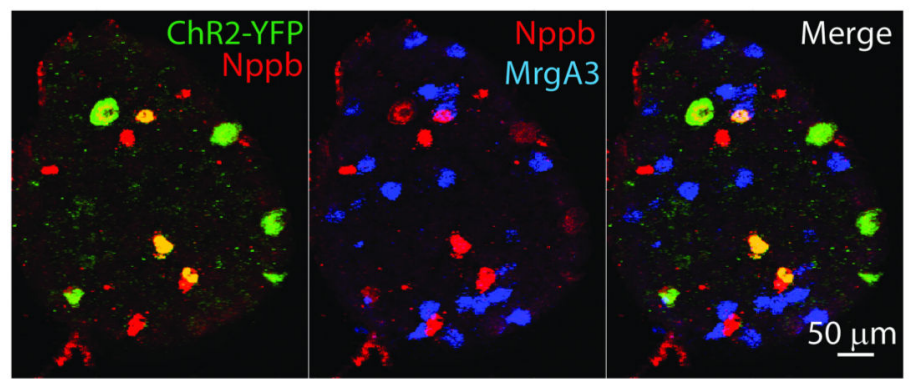

b

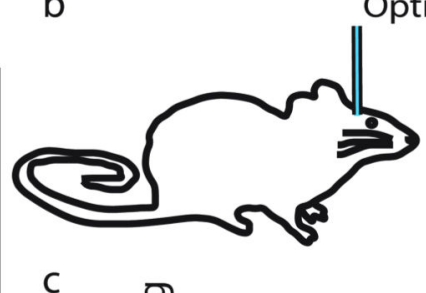

C

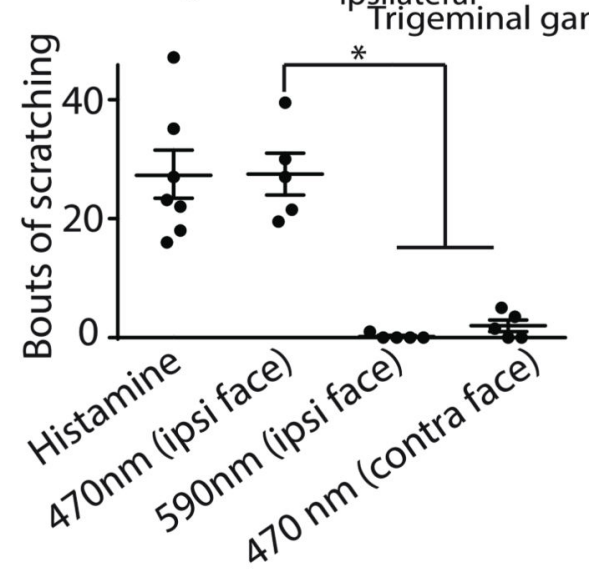

Figure 2. Somatostatin-expressing primary afferent neurons are sufficient to trigger itchbehavior.

A, triple label ISH reveals that in $S_{s t}{ }^{\mathrm{Cre}}$;Ai32 mice expression of ChR2-YFP (green) occurs largely in Nppb-neurons (red). MrgA3-neurons (blue) are separate from both Nppb and ChR2-YFP positive neurons. Similar results were obtained from 3 mice. B, schematic diagram illustrating the strategy employed to optogenetically activate trigeminal ganglion somatostatin-expressing neurons that innervate the face. The implanted fiber optic cannula (indicated as an outlined blue line) was passed through the brain to a position approximately $1 \mathrm{~mm}$ dorsal to the trigeminal ganglion and fixed in place with dental cement. $\mathrm{C}$, unilateral optogenetic activation of the trigeminal ganglion of $S_{s} C^{\mathrm{Cr}}$;Ai32 animals with $470 \mathrm{~nm}$ illumination generated similar numbers of scratch bouts to that elicited by intradermal administration of histamine $(100 \mu \mathrm{g})$, but did not induce scratching of the contralateral cheek. In addition, while optogenetic stimulation of $\mathrm{Ss}_{\boldsymbol{C}}{ }^{\mathrm{Cre}}$;Ai32 neurons did not evoke cheek wipes, histamine injection elicited 6.2 wipes \pm 1.53 (mean \pm SEM). Activation with $590 \mathrm{~nm}$ light evoked minimal scratching bouts. Significant differences were assessed using one-way repeated measure ANOVA with post hoc Sidak tests $\left(\mathrm{t}_{2,16}=3.139\right.$, $* \mathrm{p}=0.0001$ for both comparisons). Data represent means \pm SEM ( $n=5$ animals optogenetic experiments and $\mathrm{n}=7$ histamine cheek assay C57BL/6 mice). 


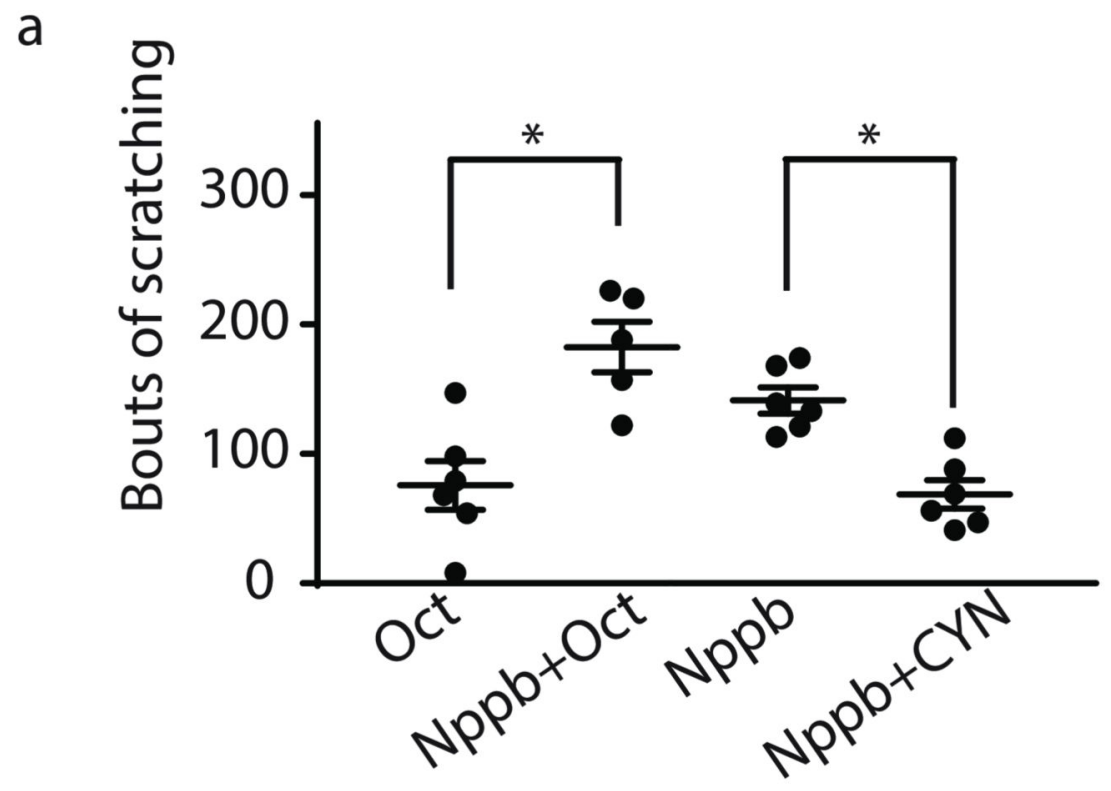

b

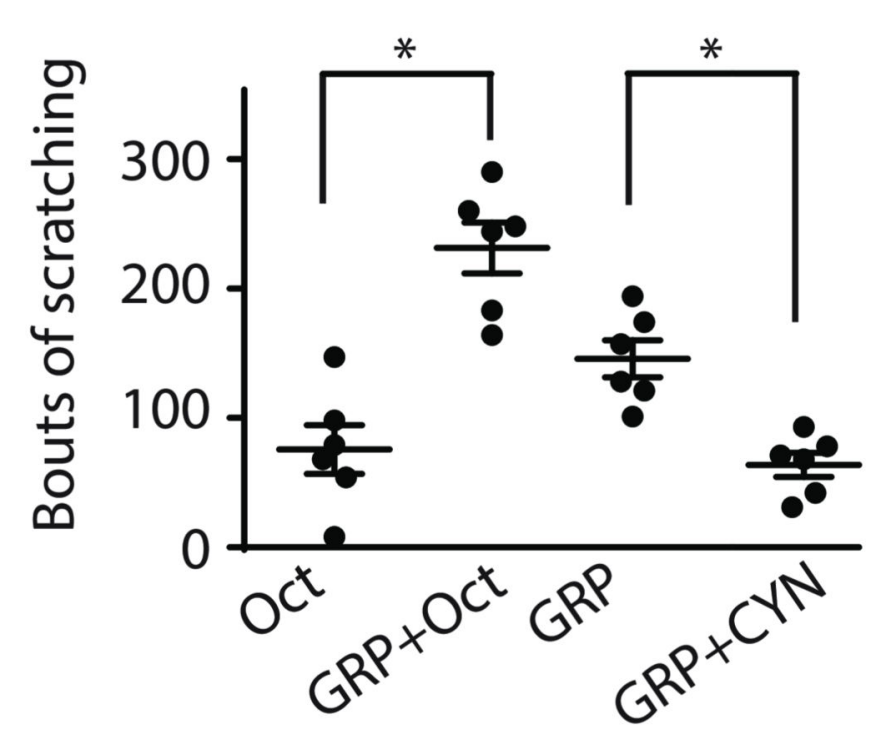

C

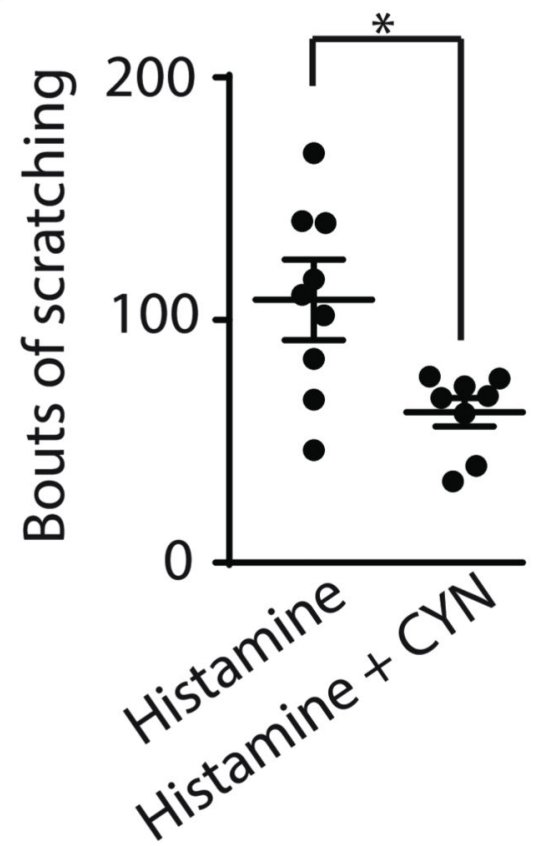

Figure 3. Modulation of Nppb- and GRP-induced itch responses by somatostatin receptor agonist and antagonist.

Scratching bouts induced by intrathecal administration of: A, Nppb (5 $\mu \mathrm{g})$, octreotide (10 $\mathrm{ng}$ ), a combination of $\mathrm{Nppb}$ and octreotide, or Nppb and the somatostatin agonist CYN154806 (1 $\mu \mathrm{g})$; B, GRP (1 nmole), octreotide (10 ng), a combination of GRP and octreotide (10 ng), or GRP and CYN154806 (1 $\mu \mathrm{g})$; C, histamine (100 $\mu \mathrm{g})$, or a combination of histamine and CYN154806 (1 $\mu \mathrm{g})$ revealed that Nppb- and GRP-evoked itch behavior is significantly potentiated by octreotide and attenuated by CYN154806 (A, B). In addition, CYN154806 significantly attenuated histamine induced scratching. Significant differences 
for A and B were assessed using one-way ANOVA with post hoc Sidak tests: Octreotide induced scratching was significantly changed by the addition of Nppb $\left({ }^{*} \mathrm{p}=0.0002\right)$ and Nppb elicited scratching was significantly reduced by CYN ( $* \mathrm{p}=0.0053), \mathrm{F}_{3,19}=0.6796$. Octreotide induced scratching was significantly changed by the addition of GRP $(* \mathrm{p}=$ $0.0001)$ and GRP elicited scratching was significantly reduced by CYN ( $* \mathrm{p}=0.0036) \mathrm{F}_{3,20}=$ 0.5998. Data represent means \pm SEM $(n=6,5,6,6,6,6,6$, and 6). Significant differences for $\mathrm{C}$ were assessed using two-sided unpaired Student's t-test $\left({ }^{*} \mathrm{p}=0.002\right)$. Data represent means $\pm \operatorname{SEM}(\mathrm{n}=9$ and 8$)$. 

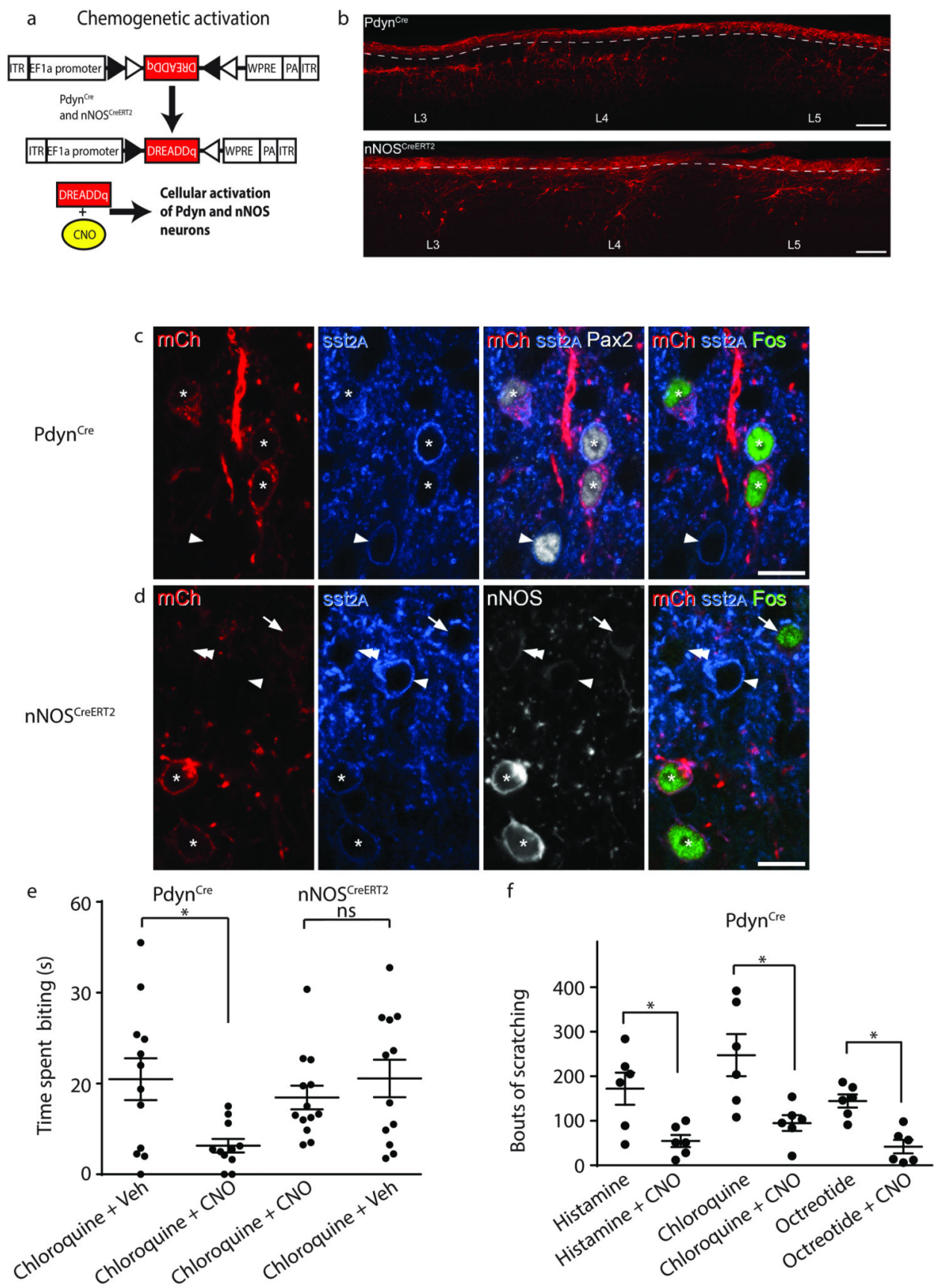

Figure 4. Spinal cord dynorphin neurons modulate itch and are downstream of the site of action of somatostatin.

A, schematic diagram of the viral-based strategy employed to chemogenetically activate spinal cord neurons expressing dynorphin or nNOS. B, sagittal sections stained for mCherry showing that intraspinal injection of the AAV in $P d y n^{\mathrm{Cre}}$ and $n N O S^{\mathrm{Cre}}$ mice produced expression with the expected distribution in spinal cord segments L3-L5, which innervate the hind-limb including the calf. Scale $=200 \mu \mathrm{m} . \mathrm{C}$, Chemogenetic activation in the PdynCre mouse. A transverse section of spinal cord taken from a $P d y n{ }^{C r e}$ mouse that had been injected with AAV2-flex-hM3Dq-mCherry and treated with CNO 2 hours prior to perfusion 
fixation. The section was immunostained to reveal mCherry ( $\mathrm{mCh}$, red), the somatostatin receptor $\mathrm{Sst}_{2 \mathrm{a}}$ (blue), Pax2 (gray) and Fos (green). Asterisks (*) show the cell bodies of 3 neurons that express hM3Dq-mCherry, Sst $_{2 \mathrm{a}}$ receptor, Pax2 and Fos, indicating chemogenetic activation of inhibitory ( $\mathrm{Sst}_{2 \mathrm{a}}$-expressing) dynorphin cells. Similar results were obtained in experiments on 3 CNO-treated animals (see Figure S3 for numbers).

Arrowhead points to a $\mathrm{Pax}^{+}$(inhibitory) $\mathrm{Sst}_{2 \mathrm{a}}$-expressing neuron that lacks mCherry and this cell was not Fos-positive. Scale $=10 \mu \mathrm{m}$. D, Chemogenetic activation in the $n N O S^{\text {CreERT2 }}$ mouse. Transverse section of spinal cord taken from a $n N O S^{\mathrm{CreERT} 2}$ mouse injected with AAV2-flex-hM3Dq-mCherry and treated with CNO 2 hours prior to perfusion fixation. The section was immunostained to reveal mCherry (red), $\mathrm{Sst}_{2 \mathrm{a}}$ (blue), nNOS (gray) and Fos (green). Five cells showing varying levels of nNOS-immunoreactivity are visible. Two of these (asterisks) are stained for mCherry and $\mathrm{Sst}_{2 \mathrm{a}}$ (inhibitory nNOS cells) and these are Fos-positive. Of the 3 cells with weak nNOS-immunoreactivity, one (arrow) is positive for mCherry and Fos, but lacks $\mathrm{Sst}_{2 \mathrm{a}}$, and is therefore likely an excitatory interneuron. The other two are not labelled with either mCherry or Fos: one of these is an $\mathbf{S s t}_{2 \mathrm{a}}$-positive inhibitory neuron (single arrowhead), while the other lacks $\mathrm{Sst}_{2 \mathrm{a}}$ and is therefore likely to be an excitatory neuron (double arrowhead). This shows chemogenetic activation of nNOS cells, including inhibitory ( $\mathrm{Sst}_{2 \mathrm{a}}$-expressing) interneurons. Similar results were obtained in experiments on 3 CNO-treated animals (see Figure S3 for numbers). Scale $=20 \mu \mathrm{m}$. E. The time spent biting the calf in response to intradermal injection of chloroquine $(100 \mu \mathrm{g})$ was reduced following chemogenetic activation (CNO) in $P d y n^{\mathrm{Cre}}$ mice, but there was no effect on itch responses in $n N O S^{\text {CreERT2 }}$ animals. Significant differences were assessed using twosided unpaired Student $\mathrm{t}$-tests $\left(\mathrm{t}_{21}=2.92,{ }^{*} \mathrm{p}=0.0082\right.$; and $\mathrm{t}_{23}=0.875, \mathrm{p}=0.391 \mathrm{~ns}$ not significant). Data represent means \pm SEM ( $\mathrm{n}=11,12,12$, and 13 animals, for $P d y n^{\mathrm{Cre}}$ mice treated with $\mathrm{CNO}$ and vehicle and for $n N O S^{\mathrm{CreERT} 2}$ mice treated with $\mathrm{CNO}$ and vehicle, respectively). mCherry-labelled injection sites (as shown in B) were verified in all of these experiments. F, DREADDq activation following intrathecal injection of AAV2-flex-hM3Dq significantly reduced numbers of itch bouts in $P d y n^{\mathrm{Cre}}$ mice injected into the nape of the neck with histamine $(100 \mu \mathrm{g})$ and chloroquine $(100 \mu \mathrm{g})$, and also when octreotide (100 ng) was administered intrathecally. Significant differences were assessed using two-sided unpaired Student t-tests $\left(\mathrm{t}_{10}=3.017,3.053,4.861,{ }^{*} \mathrm{p}=0.013,0.0122\right.$, and 0.0007). Data represent means \pm SEM ( $n=6$ animals). 

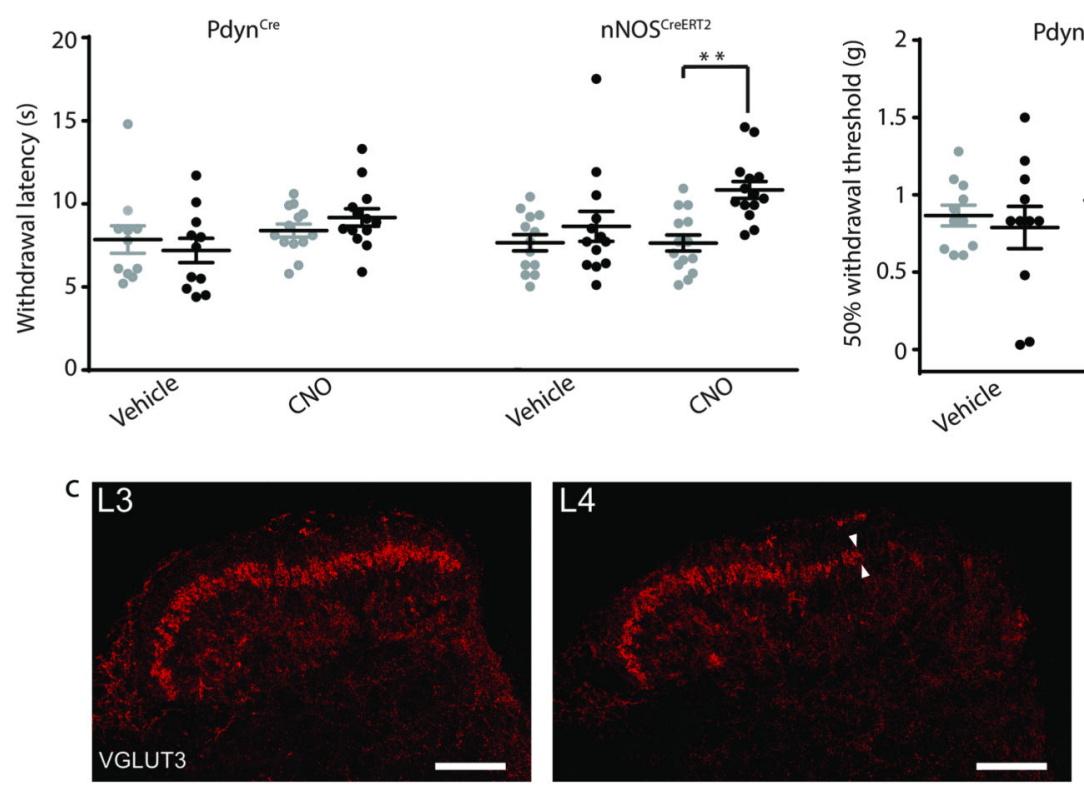

nNOSCreERT2
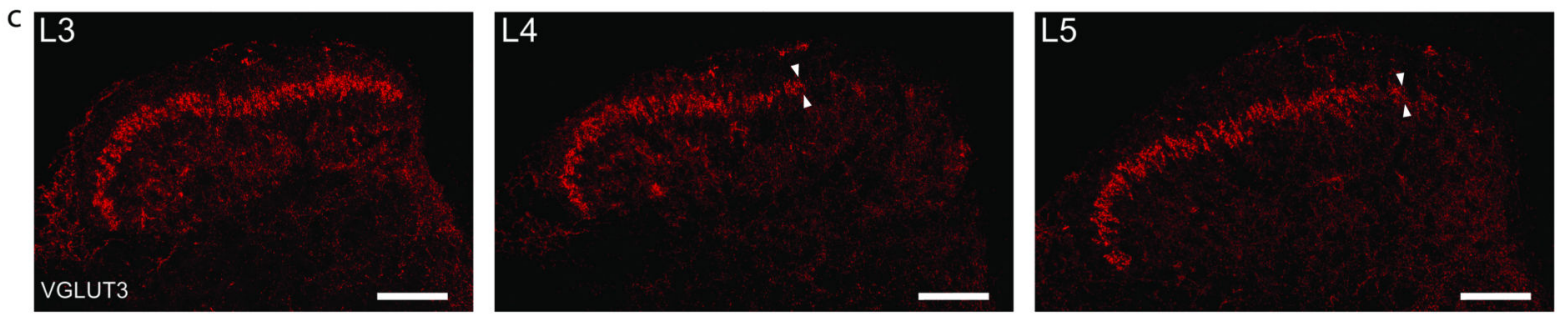
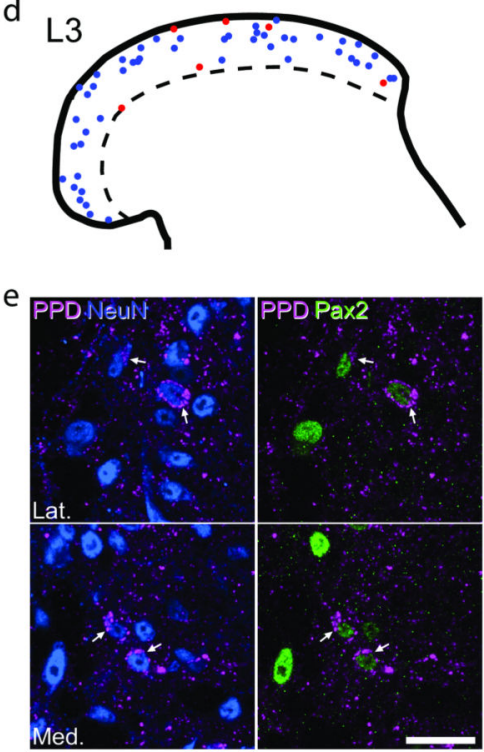

$\llcorner 4$

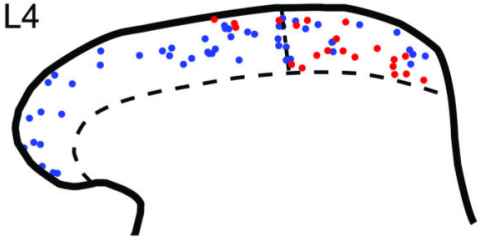

$f$
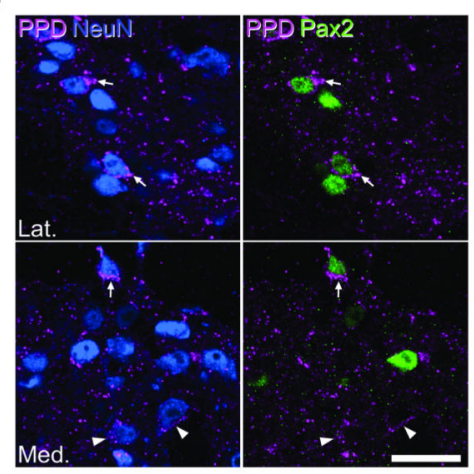
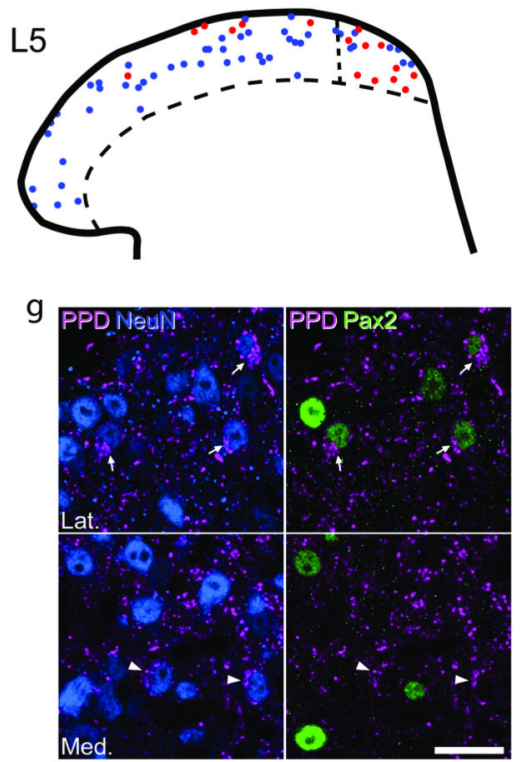

Figure 5. Chemogenetic activation of $P d y n{ }^{\mathrm{Cre}}$ and $n N O S{ }^{\mathrm{CreERT} 2}$ neurons modulates responses to heat and mechanical stimuli and the pro-nociceptive effect of dynorphin neuron activation likely involves excitatory interneurons.

A, Hargreaves assays revealed that while responses to heat stimulation were unaffected in mice in which dynorphin neurons were chemogenetically activated (CNO), sensitivity was significantly reduced in animals in which nNOS neurons were activated. B, von-Frey tests showed that chemogenetic activation (CNO) of dynorphin neurons elicited mechanical hyperalgesia, while activation of nNOS neurons caused significantly reduced sensitivity to mechanical stimulation. In all cases behavioral results of testing the paw ipsilateral to spinal 
AAV injection in vehicle- and CNO-treated mice (post-surgery) were compared with results from the same animals obtained before intraspinal injection of the AAV (pre-surgery).

Significant differences were assessed using 2-way ANOVA with post hoc Sidak tests $\left(\mathrm{F}_{1,25}\right.$ $\left.=4.566, * \mathrm{p}=0.0117, \mathrm{~F}_{1,25}=9.855, * * \mathrm{p}=0.0039, \mathrm{~F}_{1,25}=19.25, * * * \mathrm{p}=0.000012\right)$. Data represent means $\pm \operatorname{SEM}\left(\mathrm{n}=13,11,14\right.$, and 13 animals, for Pdyn ${ }^{\mathrm{Cre}}$ mice treated with CNO and vehicle and for $\mathrm{nNOS}^{\mathrm{CreERT} 2}$ mice treated with $\mathrm{CNO}$ and vehicle, respectively). C-G. Plots of the distribution of excitatory and inhibitory dynorphin-expressing cells show that the excitatory cells are highly concentrated in the region innervated from glabrous skin. C. Immunostaining for VGLUT3 was used to reveal the extent of innervation from hairy skin, since C-low threshold mechanoreceptors (which express VGLUT3) are largely absent from glabrous skin. The VGLUT3 band occupies the whole mediolateral extent of the superficial dorsal horn at L3, but is absent from the medial part of the L4 and L5 segments, which are innervated by afferents from glabrous skin. The junction between these regions is marked (arrowheads). Similar results were obtained from 3 mice. D The distribution of preprodynorphin (PPD)-immunoreactive cells that are inhibitory (Pax2-positive, blue circles) and excitatory (Pax2-negative, red circles) plotted onto outlines of the L3-L5 segments (data pooled from 3 mice). The junction between hairy and glabrous skin territories is marked by a dashed line. Note that excitatory PPD cells are concentrated in the glabrous skin territory, and are much less numerous in regions innervated from hairy skin, including the L3 segment. E-G. Examples of immunostaining for PPD (magenta), NeuN (blue) and Pax2 (green) in the medial (Med) and lateral (Lat) parts of the L3, L4 and L5 segments, respectively. Examples of Pax2-positive PPD-immunoreactive neurons are indicated with arrows, and some Pax2-negative PPD-immunoreactive cells are shown with arrowheads. Similar results were obtained from 3 mice. Scale bars $C=100 \mu \mathrm{m}, \mathrm{E}-\mathrm{G}=20$ $\mu \mathrm{m}$. 


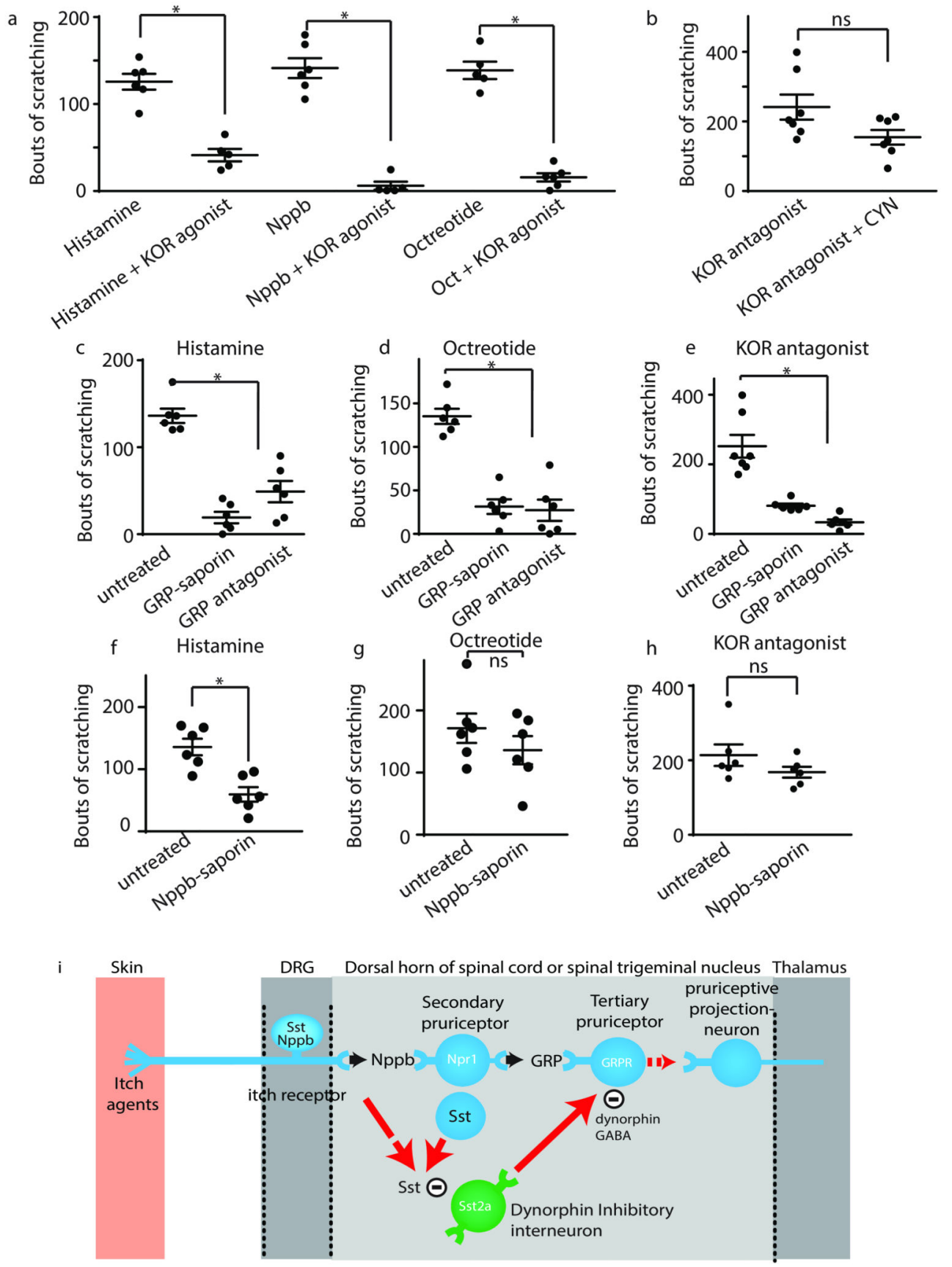

Figure 6. Somatostatin acts upstream of dynorphin-expressing inhibitory neurons, which interact with the Nppb-itch pathway at the level of GRPR-neurons.

A, itch-responses to intradermally injected histamine $(100 \mu \mathrm{g})$, and intrathecally administered Nppb $(5 \mu \mathrm{g})$ and octreotide (100ng) were significantly attenuated when the kappa opioid receptor (KOR) agonist ICI199441 (100ng) was co-administered. Significant differences were assessed using two-sided unpaired Student $\mathrm{t}$-tests $\left(\mathrm{t}_{9}=7.059, \mathrm{t}_{10}=10.14, \mathrm{t}_{9}\right.$ $=11.78,{ }^{*} \mathrm{p}=0.0001$ for all). Data represent means $\pm \operatorname{SEM}(\mathrm{n}=6,5,6,6,5$, and 6 animals). B, The somatostatin receptor Sst2 antagonist CYN154806 (1 $\mu \mathrm{g})$ does not affect itchbehavior induced by the kappa opioid receptor antagonist norBinaltrorphimine $(100 \mu \mathrm{g})$, 
differences were assessed using two-sided unpaired Student t-tests $\left(t_{12}=2.708, n s p=0.06\right)$. Data represent means \pm SEM ( $n=7$ animals). C histamine (100 $\mu$ g), D octreotide (100 ng), and $\mathrm{E}$ the kappa opioid receptor antagonist norBinaltrorphimine $(100 \mu \mathrm{g})$ induced scratching bouts were reduced in mice treated with GRP-saporin, or GRPR antagonist, significant differences were assessed using one-way ANOVA with post hoc Sidak tests $\left(\mathrm{F}_{2,15}=42.48\right.$, $\mathrm{F}_{2,15}=37.87, \mathrm{~F}_{2,16}=29, * \mathrm{p}=0.0001$ for all). Data represent means $\pm \mathrm{SEM}(\mathrm{n}=6,6,6,6,6$, $6,6,7$, and 6 animals), Nppb-saporin (F-H) treatment reduced scratching bouts to histamine, but not to octreotide or norBinaltrorphimine, differences were assessed using two-sided unpaired Student $\mathrm{t}$-tests $\left(\mathrm{t}_{5}=4.953,{ }^{*} \mathrm{p}=0.004, \mathrm{t}_{5}=1.184, \mathrm{~ns} \mathrm{p}=0.29\right.$ and $\mathrm{t}_{5}=1.466, \mathrm{p}=$ 0.203). Data represent means \pm SEM ( $n=6$ animals). I, schematic diagram of proposed model of the somatostatin-mediated itch microcircuit. Broken red arrows indicate incompletely defined pathways, and blue and green circles are neurons that are identified by either the receptor, or the neuropeptide(s) they express; Sst, somatostatin, Nppb, natriuretic polypeptide b, Npr1, Natriuretic polypeptide receptor $1, \mathrm{Sst}_{2 \mathrm{a}}$, somatostatin receptor 2a, GRP, gastrin releasing peptide, and GRPR, gastrin releasing peptide receptor. 
Somatostatin conditional knockout

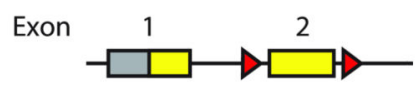

Cre-mediated excission
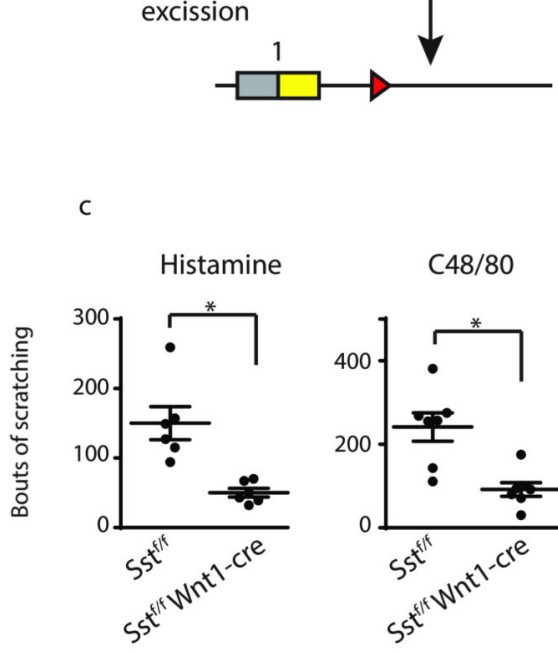

$\mathrm{C} 48 / 80$

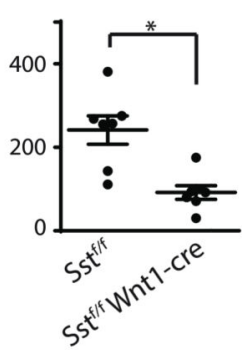

b

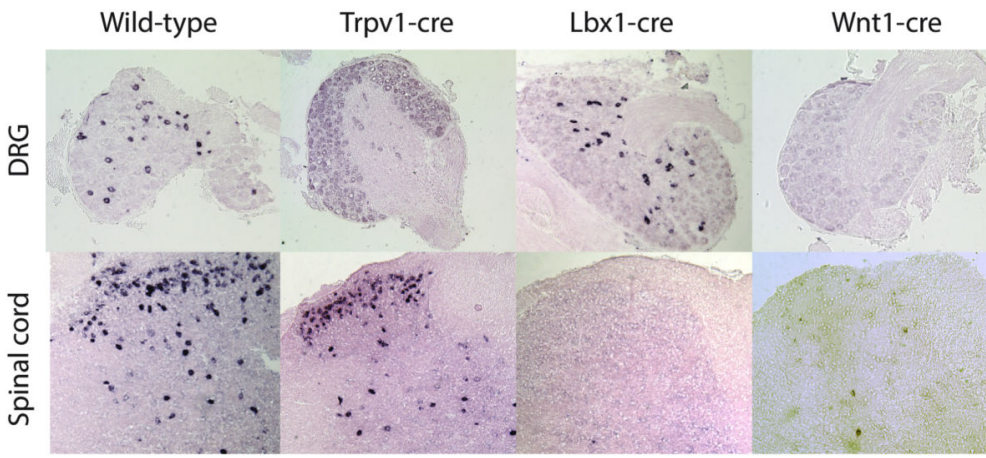

Figure 7. Somatostatin-null mice exhibit itch-related behavioral deficits to pruritogens.

A, schematic diagram depicting the genetic strategy employed to conditionally eliminate the expression of somatostatin. B, ISH of section through DRG (top row) and dorsal spinal cord (bottom row) demonstrates that $S s t^{f / f} ; \operatorname{Tr}_{p v} I^{\mathrm{Cre}}$ mice lack expression of somatostatin in DRG, $S s t^{f / \mathrm{f}} ; L b x 1^{\mathrm{Cre}}$ mice lack expression of somatostatin in the spinal cord, and that $S s t^{f / f} ; W n t I^{\text {Cre }}$ mice lack expression of somatostatin in DRG and spinal cord. Similar results were obtained from 3 mice. C, $S s t^{\text {f/f }} ; W_{n t} 1^{\text {Cre }}$ mice are much less sensitive to intradermal injection of a variety of compounds that induce itch than normal littermate controls.

Significant differences were assessed using two-sided unpaired Student t-tests $\left(\mathrm{t}_{10}=4.082\right.$, $\mathrm{t}_{12}=3.967, \mathrm{t}_{10}=2.83, \mathrm{t}_{10}=3.836, \mathrm{t}_{13}=2.368, \mathrm{t}_{10}=2.279, * \mathrm{p}=0.0022,0.0019,0.0179$, 0.0033, 0.0034, and 0.0458). Data represent means $\pm \operatorname{SEM}(\mathrm{n}=6,6,7,7,6,6,6.6,8,7,6$, and 6 animals). 

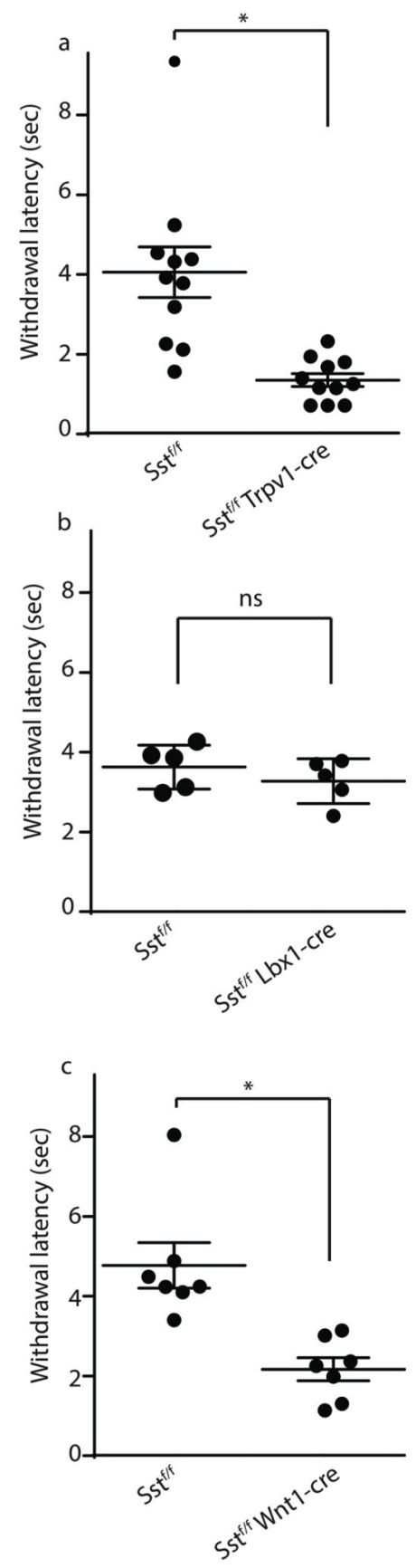

Figure 8. Elimination of somatostatin expression from primary afferent neurons increases pain sensitivity.

$S s t^{\mathrm{f} / \mathrm{f}} ; \operatorname{Trpv}^{\mathrm{Cre}}$ mice are much more sensitive to noxious heat stimulation than normal littermate controls, A. In contrast, $S s t^{\mathrm{f} / \mathrm{f}} ; L_{b x} I^{\mathrm{Cre}}$ mice exhibit similar withdrawal latency to noxious heat as normal littermate controls, B. $S s t^{f / f} ; W n t I^{\mathrm{Cre}}$ mice also display reduced latencies to noxious heat stimulation compared to normal littermate controls, C. Significant differences were assessed using two-sided unpaired Student $\mathrm{t}$-tests $\left(\mathrm{t}_{20}=4.156, \mathrm{t}_{8}=1.01, \mathrm{t}_{12}\right.$ 
$=4.059, * \mathrm{p}=0.0005,0.3421$, and 0.0016). Data represent means $\pm \operatorname{SEM}(\mathrm{n}=11,11,5,5,7$, and 7 animals). 